\title{
INTERNATIONAL PROGRAM: SUMMARY REPORT ON THE PROPERTIES OF CEMENTITIOUS WASTE FORMS
}

\section{KHLOPIN RADIUM INSTITUTE AND THE SAVANNAH RIVER NATIONAL LABORATORY}

\author{
John R. Harbour \\ Savannah River National Laboratory \\ and \\ Albert S. Aloy \\ Khlopin Radium Institute
}

March 2007

Process Science and Engineering

Savannah River National Laboratory

Aiken, SC 29808

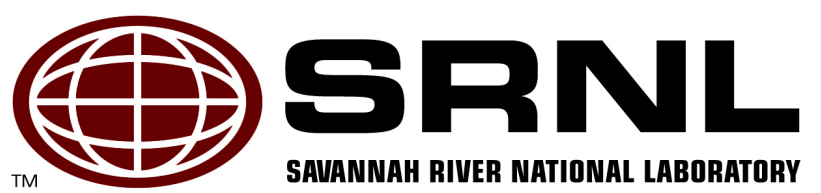




\title{
DISCLAIMER
}

This report was prepared by Washington Savannah River Company (WSRC) for the United States Department of Energy under Contract No. DE-AC09-96SR18500 and is an account of work performed under that contract. Neither the United States Department of Energy, nor WSRC, nor any of their employees makes any warranty, expressed or implied, or assumes any legal liability or responsibility for the accuracy, completeness, or usefulness, of any information, apparatus, or product or process disclosed herein or represents that its use will not infringe privately owned rights. Reference herein to any specific commercial product, process, or service by trademark, name, manufacturer or otherwise does not necessarily constitute or imply endorsement, recommendation, or favoring of same by WSRC or by the United States Government or any agency thereof. The views and opinions of the authors expressed herein do not necessarily state or reflect those of the United States Government or any agency thereof.

\author{
Printed in the United States of America \\ Prepared For \\ U.S. Department of Energy
}


Key Words: Tc-99 Retention Heat of Hydration PORFLOW ${ }^{T M}$ Modeling

Retention: Permanent

\title{
INTERNATIONAL PROGRAM: SUMMARY REPORT ON THE PROPERTIES OF CEMENTITIOUS WASTE FORMS
}

\section{KHLOPIN RADIUM INSTITUTE AND THE SAVANNAH RIVER NATIONAL LABORATORY}

\author{
John R. Harbour \\ Savannah River National Laboratory \\ and \\ Albert S. Aloy \\ Khlopin Radium Institute
}

March 2007

Process Science and Engineering Savannah River National Laboratory Aiken, SC 29808 


\section{REVIEWS AND APPROVALS}

\section{AUTHOR:}

J. R. Hafrbour, SRNL, Stabilization Science Research

Date

A. S. Aloy, Khlopin Radium Institute

Date

TECHNICAL REVIEWERS:

$\overrightarrow{\text { SRNNL, Stabilization Science Research }}$

'Date

\section{APPROVERS}

T. B. Callowav. SRŇL. Manager/Advănced Process Development

Date

R. E. Edwards, SRNL, Manager, Process Science and Engineering

Date 


\section{EXECUTIVE SUMMARY}

This report provides a summary of the results on the properties of cementitious waste forms obtained as part of the International Program. In particular, this report focuses on the results of Task 4 of the Program that was initially entitled "Improved Retention of Key Contaminants of Concern in Low Temperature Immobilized Waste Forms". Task 4 was a joint program between Khlopin Radium Institute and the Savannah River National Laboratory. The task evolved during this period into a study of cementitious waste forms with an expanded scope that included heat of hydration and fate and transport modeling.

This report provides the results for Task 4 of the International Program as of the end of FY06 at which time funding for Task 4 was discontinued due to the needs of higher priority tasks within the International Program. Consequently, some of the subtasks were only partially completed, but it was considered important to capture the results up to this point in time. Therefore, this report serves as the closeout report for Task 4.

The degree of immobilization of Tc-99 within the Saltstone waste form was measured through monolithic and crushed grout leaching tests. An effective diffusion coefficient of $4.8 \times 10^{-12}$ (Leach Index of 11.4) was measured using the ANSI/ANS-16.1 protocol which is comparable with values obtained for tank closure grouts using a dilute salt solution. The leaching results show that, in the presence of concentrated salt solutions such as those that will be processed at the Saltstone Production Facility, blast furnace slag can effectively reduce pertechnetate to the immobile +4 oxidation state.

Leaching tests were also initiated to determine the degree of immobilization of selenium in the Saltstone waste form. Results were obtained for the upper bound of projected selenium concentration $\left(\sim 5 \times 10^{-3} \mathrm{M}\right)$ in the salt solution that will be treated at Saltstone. The ANSI/ANS 16.1 leaching tests provided a value for the effective diffusivity of $\sim 5 \times 10^{-9} \mathrm{~cm}^{2} / \mathrm{sec}$ and a corresponding leaching index of $\sim 8.2$. Leaching tests at the lower bound of concentration and the leaching tests to determine the impact of redox (selenium exists in two oxidation states, selenite $\left(\mathrm{SeO}_{3}{ }^{-2}\right)$ and selenate $\left.\left(\mathrm{SeO}_{4}{ }^{-2}\right)\right)$ on $\mathrm{Se}-79$ release were not completed due to lack of funding.

The heat of hydration of a Saltstone mix limits the processing rate at the Saltstone Production Facility. Therefore, reduction in the heat of hydration of a Saltstone formulation that still complies with the remaining property requirements would provide for a greater rate of production. Initial testing for this task was completed.

There was good agreement between the isothermal measurements of heat of hydration performed as part of this task with previous measurements of heat of hydration of Saltstone obtained adiabatically over the same 80 hour time period. The slightly higher heat of hydration per gram of cementitious material measured adiabatically can be explained by the higher temperatures achieved during the adiabatic measurements.

The isothermal measurements reveal additional details of the heat generation process that were not evident in the adiabatic measurements. An initial heat release in the first minutes was 
observed isothermally. A second peak at about 5 hours was also observed isothermally that was not detected adiabatically. The major heat releases in the 10 to 30 hour period were observed by both techniques but at slightly different times and ratios of the two major peaks that comprise that region.

The degree of reaction was calculated from these measurements based upon the value assigned to maximum hydration. Using the Schmidt method, the degree of reaction after 80 hours was 36\% complete by isothermal calorimetry and $46 \%$ complete by adiabatic calorimetry. Using the theoretical maximum wherein the fly ash and slag are hydraulically equivalent to the portland cement, the degree of reaction after 80 hours was $20 \%$ complete by isothermal calorimetry and $25 \%$ complete by adiabatic calorimetry. This time dependence of the heat of hydration is used at SRNL as input into a model that predicts the temperature rise within the Saltstone vaults.

The transport of radionuclides and oxygen within the Saltstone waste form and surrounding concrete vault were calculated using the PORFLOW ${ }^{\mathrm{TM}}$ code (Performance Assessment calculations at Savannah River Site also use this commercially available code). The Tc-99 effective diffusivity, obtained through leaching tests, was used as input into the code to predict release of Tc-99 from the waste form and from the vault as a function of time $(10,000$ year compliance period). A sensitivity study was performed to determine the Tc-99 release as a function of changes to the hydraulic conductivity and effective diffusivity of Tc-99. These results are included in this report. An alternative approach was implemented using exponential functions to approximate the time dependence of the hydraulic conductivity and effective diffusivity as the waste form ages. The exponential dependence was introduced to reflect deterioration or enhancement of the Saltstone properties with time. 


\section{TABLE OF CONTENTS}

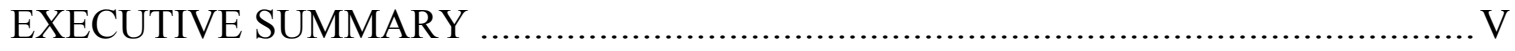

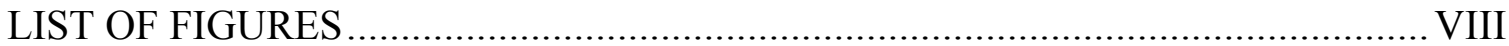

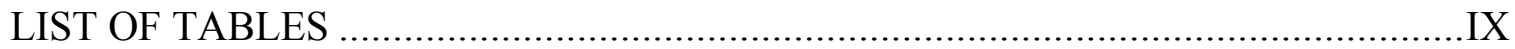

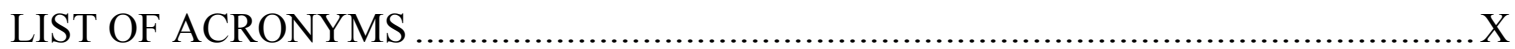

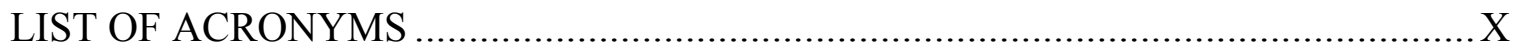

1.0 INTRODUCTION

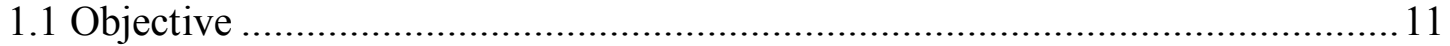

2.0 FINAL STATUS TC-99 LEACHING FROM SALTSTONE ..................................11

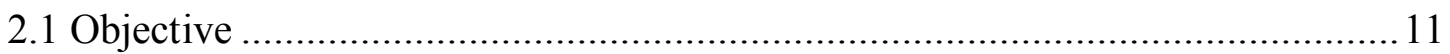

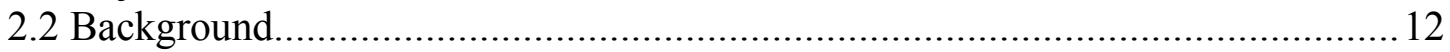

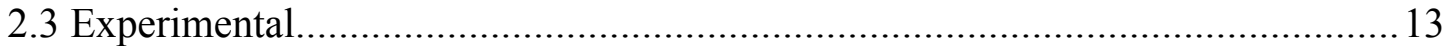

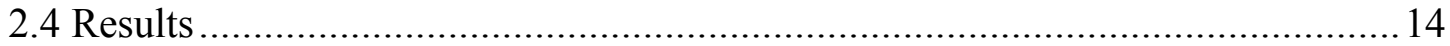

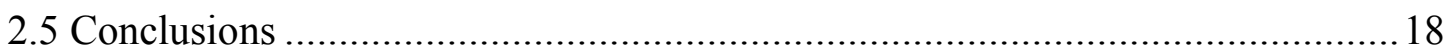

3.0 FINAL STATUS SE-79 LEACHING FROM SALTSTONE ….............................18

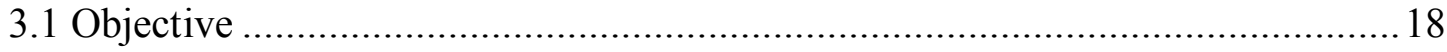

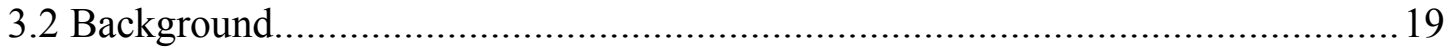

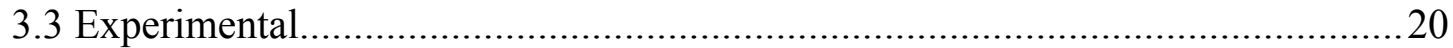

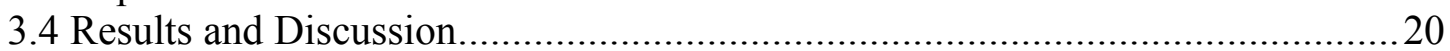

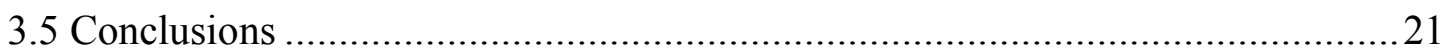

4.0 FINAL STATUS OF HEAT OF HYDRATION FOR SALTSTONE ………............21

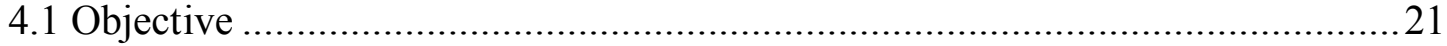

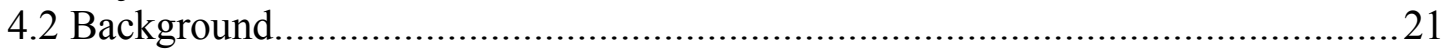

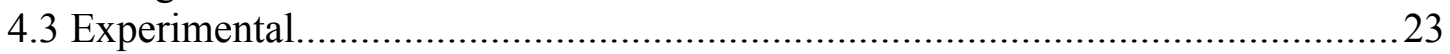

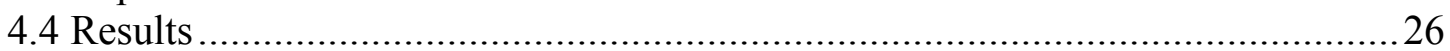

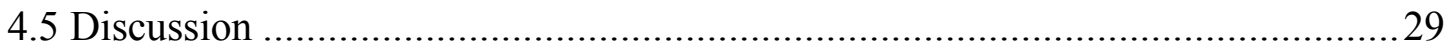

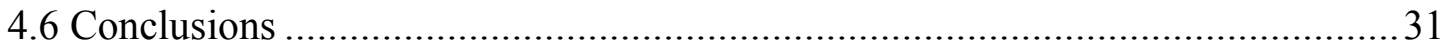

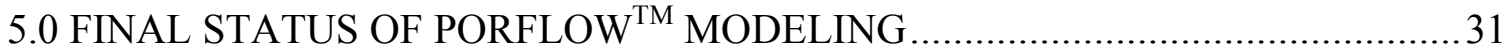

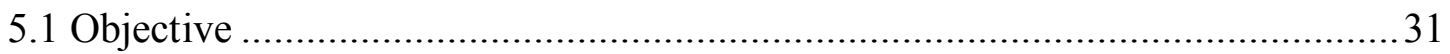

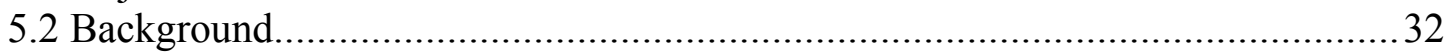

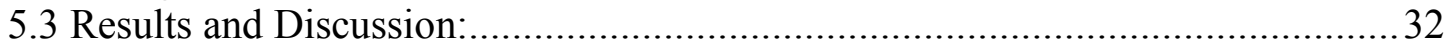

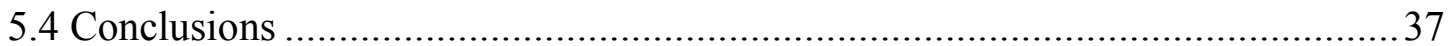

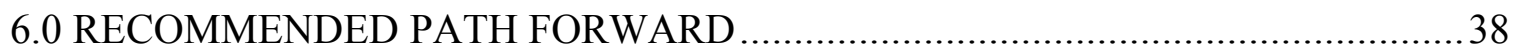

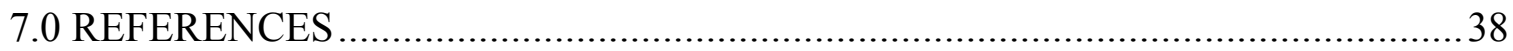




\section{LIST OF FIGURES}

Figure 2-1 Tc-99 distribution between the solution and the solid phase 16

Figure 2-2 Percent of Tc-99 leached from crushed grout samples as a function of time. 17

Figure 4-1 Block diagram of the isothermal calorimeter used in this task 24

Figure 4-2 Calorimetric Curve of Cement Mixture \# 1(a) (Water/Premix=0.6). UV is volts. 26

Figure 4-3 Calorimetric Curve of Cement Mixture \# 1(a) (Water/Premix=0.6). UV is volts. 26

Figure 4-4 Calorimetric Curve of Cement Mixture \# 1(a) (Water/Premix=0.6). UV is volts. 27

Figure 4-5 Calorimetric Curve of Cement Mixture \# 1(a) (Water/Premix=0.6). UV is volts. 27

Figure 4-6 Heat generation for Saltstone as measured using adiabatic calorimetry [19] 29

Figure 5-1 Meq e-/g solid after 250,000 Years. 33

Figure 5-2 Percent of Tc-99 leached from Saltstone at two values of Hydraulic Conductivity (k) as shown in the Figure.

Figure 5-3 Percent of Tc-99 released from the vault as a function of Saltstone diffusivity. The Vault Concrete Diffusivity was set equal to $10^{-8} \mathrm{~cm}^{2} / \mathrm{sec}$ for these calculations.

Figure 5-4. Percent of Tc-99 released from the Saltstone Vault as a function of equal changes in both the Vault Concrete Diffusivity and the Grout/Saltstone Diffusivity.

Figure 5-5 Percent of Tc-99 Released from the Saltstone Vault at Various Rates of Cement Transformations with Time. 


\section{LIST OF TABLES}

Table 2-1 Chemical composition of the salt simulant used to make Saltstone....................... 13

Table 2-2 Grout compositions of the Samples 1 through 5 .......................................... 14

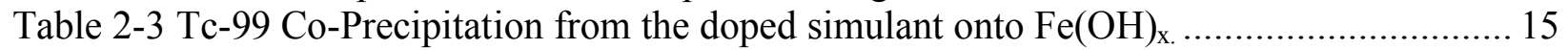

Table 2-4 Tc-99 oxidation and desorption under aerobic conditions................................... 16

Table 4-1 Cementitious content of MCU and DDA mixes at a water to premix ratio of $0.60 \ldots .22$

Table 4-2 Simulant Solution Composition ...................................................................... 25

Table 4-3 Chemical Composition of Ferro-Spinel Fly Ash................................................. 25

Table 4-4 Mass Ratios in Cement Paste Samples ......................................................... 25

Table 4-5 Specific Heat Release in Various Cement Systems................................................. 28 


\section{LIST OF ACRONYMS}

\begin{tabular}{|l|l|}
\hline ANS & American Nuclear Society \\
\hline ANSI & American National Standards Institute \\
\hline ASTM & American Society for Testing and Materials \\
\hline BFS & Blast Furnace Slag \\
\hline DDA & Deliquification, Dissolution and Adjustment \\
\hline EMF & Electromotive Force \\
\hline EXAFS & Extended X-ray Absorption Fine Structure \\
\hline FA & Fly Ash \\
\hline ICP-MS & Inductively Coupled Plasma - Mass Spectrometry \\
\hline MCU & Modular Caustic Side Solvent Extraction Unit \\
\hline OPC & Ordinary Portland Cement \\
\hline SRNL & Savannah River National Laboratory \\
\hline SRS & Savannah River Site \\
\hline SDF & Saltstone Disposal Facility \\
\hline SPF & Saltstone Processing Facility \\
\hline SWPF & Salt Waste Processing Facility \\
\hline XANES & X-ray Absorption Near Edge Structure \\
\hline
\end{tabular}




\subsection{INTRODUCTION}

\subsection{Objective}

This report provides a summary of the results on the properties of cementitious waste forms, obtained as part of the International Program. In particular, this report focuses on the results of Task 4 of the Program that was initially entitled "Improved Retention of Key Contaminants of Concern in Low Temperature Immobilized Waste Forms". Task 4 was a joint program between Khlopin Radium Institute and the Savannah River National Laboratory. The task evolved during this period into a study of cementitious waste forms with an expanded scope that included heat of hydration and Fate and Transport Modeling.

This report provides the results for Task 4 as of the end of FY06 at which time funding for Task 4 ended. Consequently, some of the subtasks were only partially completed, but it was considered important to capture the results up to this point in time. Therefore, this report serves as the closeout report for Task 4 .

\subsection{FINAL STATUS TC-99 LEACHING FROM SALTSTONE}

\subsection{Objective}

The overall objective of this task was to measure retention of Tc-99 in cured Saltstone samples [1] through leaching tests that measure Tc-99 release into the leachate solution as a function of time. This testing used a reference Saltstone formulation with a simulated waste stream (doped with Tc-99) that reflects an average projected composition of the feed stream to the Saltstone Production Facility[2]. It is a concentrated salt solution with a sodium Molarity of $\sim 5 \mathrm{M}$. Specifically the objective was achieved by:

1. Measuring the Tc-99 leaching performance of monolithic waste forms to determine the effective diffusion coefficient (ANSI/ANS 16.1) in these highly concentrated salt solutions

2. Determining whether pretreatment of the waste stream can lead to a reduction in the Tc99 leaching from the grout waste form (Saltstone) compared to the current approach of using blast furnace slag only as the reductant for pertechnetate

3. Measuring the Tc-99 leaching using crushed grout samples (accelerated leaching) to more readily determine the effects of added reductants and oxygen on leaching performance 


\subsection{Background}

The predictions of dose at the point of compliance in the Performance Assessment for the Saltstone vaults depend significantly on Tc-99 release from the Saltstone [3]. The pertechnetate anion $\left(\mathrm{TcO}_{4}{ }^{-}\right)$is the stable form of technetium in salt waste streams containing dissolved oxygen, is very soluble in the salt solutions, and is highly mobile. The 212,000 years half life for Tc-99 also makes Tc-99 important since this isotope decays over the entire 10,000 year period of compliance. In order to reduce the mobility of pertechnetate, the approach has been to chemically reduce Tc(VII) to the Tc(IV) state through inclusion of blast furnace slag [4] as part of the cementitious materials used to form the grout [5]. The resultant Tc(IV) species are essentially insoluble and will only be transported out of the waste form if they are oxidized back to the Tc(VII) state.

Spectroscopic analysis of grout waste forms containing Tc-99 provides information on the speciation of technetium as a function of added reductants and oxidants (e.g., nitrate and oxygen) [6]. The techniques employed are extended X-ray absorption fine structure (EXAFS) spectroscopy and X-ray absorption near edge structure (XANES) spectroscopy. Most of these studies used an added reductant, sodium sulfide, and consequently, the reduced species identified by EXAFS and XANES were technetium sulfur compounds represented by the formulas $\mathrm{Tc}_{3} \mathrm{~S}_{10}$ or $\mathrm{Tc}_{2} \mathrm{~S}_{7}$. Lukens et al [6] argue that these two species are identical and contain technetium in the reduced state, $\mathrm{Tc}(\mathrm{IV})$.

Spectroscopic results without added sulfide show that not all of the Tc(VII) is reduced to Tc(IV) by the blast furnace slag in the cured mixes[7]. The authors suggest that the reducing species on blast furnace slag is a sulfur compound that produces species similar to that observed when sodium sulfide is added to the mix. The EXAFS and XANES techniques also revealed that mixes prepared with no blast furnace slag (portland cement only) showed very little reduction of the pertechnetate. The authors showed that as long as oxygen is excluded from the grout waste form, the $\mathrm{Tc}_{3} \mathrm{~S}_{10}$ form is stable. Conversely, if oxygen is present, then the Tc(IV) species is oxidized back to the pertechnetate ion at a rate dependent on the value of the oxygen diffusivity in the Saltstone. Typical values of oxygen diffusivity in grouts make this re-oxidation a very slow process [6].

It was also demonstrated spectroscopically that nitrate does not oxidize the reduced technetium species in the grout waste form over the time period of their experiments (months) [6]. Nitrate is an oxidant and is dissolved within the pore liquid of the Saltstone waste form.

An alternative measure of technetium retention in the grout waste form can be obtained through leaching tests. These tests provide insight into the release of technetium under various conditions as a function of time. Leaching tests were carried out in 2004 with grout formulations that are similar to the Saltstone formulation but with waste streams that are less concentrated in salts than Saltstone feed [8]. Monolithic leaching tests using the ANSI/ANS 16.1 testing protocol [9] revealed an effective diffusion coefficient of $1.3 \mathrm{E}-09$ to $1.1 \mathrm{E}-14 \mathrm{~cm}^{2} / \mathrm{sec}$ for the $95 \%$ confidence interval. The effective diffusion coefficient measured by this technique is thought to reflect oxygen diffusion into the cured grout, oxidation of the $\mathrm{Tc}(\mathrm{IV})$ by oxygen to 
Tc(VII), diffusion of the pertechnetate to the surface of the waste form, and release of pertechnetate to the solution.

This work extends the leaching tests to concentrated salt solutions typical of feed to Saltstone and measures the effective diffusion coefficient as well as the effectiveness of pretreatment of the waste stream to the overall leaching results.

A summary of the Tc-99 leaching results were presented at the Material Research Society Fall Meeting in 2006 in the Symposium on the Scientific Basis for Radioactive Waste Management XXX [10].

\subsection{Experimental}

Materials The simulant used in the testing had a total Na Molarity of 4.93. The composition of the Saltstone simulant is provided in Table 2-1.

Table 2-1 Chemical composition of the salt simulant used to make Saltstone

\begin{tabular}{|c|c|}
\hline \multicolumn{2}{|c|}{ SALTSTONE SIMULANT } \\
\hline Compound & Molarity \\
\hline & Moles/Liter \\
\hline $\mathrm{NaOH}$ & 0.78 \\
\hline $\mathrm{NaNO}_{3}$ & 2.04 \\
\hline $\mathrm{NaNO}_{2}$ & 0.54 \\
\hline $\mathrm{Na}_{2} \mathrm{CO}_{3}$ & 0.29 \\
\hline $\mathrm{Na}_{2} \mathrm{SO}_{4}$ & 0.22 \\
\hline $\mathrm{NaAl}(\mathrm{OH})_{4}$ & 0.32 \\
\hline $\mathrm{Na} \mathrm{PO}_{4}$ & 0.04 \\
\hline $\mathrm{NaCl}$ & 0.11 \\
\hline & \\
\hline Total $\mathrm{Na}$ Molarity & 4.93 \\
\hline
\end{tabular}

The Tc-99 solution (as pertechnetate) was obtained at KRI as a solution of dilute nitric acid. For these experiments, the concentration of Tc-99 was approximately $6 \times 10^{+5} \mathrm{~Bq} / \mathrm{L}$ or $1.6 \times 10^{-5}$ $\mathrm{Ci} / \mathrm{L}$.

The portland cement (PS-500) was obtained from Pikalevskij Cement Plant. Clinoptilolite was used at $5 \mathrm{wt} . \%$ in some of the formulations due to the fact that the initial efforts also focused on Cs-137 retention in the mixes. This additive has no effect on the Tc-99 reduction and immobilization. For the monolithic leaching tests, metallurgical dust was added at $5 \%$ by weight of the premix blend. 
Pretreatment For the pretreatment experiments, $8 \mathrm{~mL}$ of the Tc-99 spiked simulant were placed into $12 \mathrm{~mL}$ plastic vials. Then, $0.2 \mathrm{~mL}$ of Fe(III) nitrate or Fe(II) sulfate solutions were added. The vials were capped, shaken for 5 minutes, and centrifuged. The supernate was then sampled and the Tc-99 concentration, $\mathrm{E}_{\mathrm{h}}$, and $\mathrm{pH}$ were measured.

The stability of the precipitated $\left[\mathrm{Fe}(\mathrm{OH})_{\mathrm{x}} \mathrm{Tc}(\mathrm{IV})\right]$ system to re-oxidation under aerobic conditions was determined by the following experimental process. Thirty $\mathrm{mL}$ of the spiked simulant were introduced into $50 \mathrm{~mL}$ vials and $\mathrm{FeSO}_{4} \cdot 7 \mathrm{H}_{2} \mathrm{O}$ was then added to achieve a final $\left[\mathrm{Fe}^{2+}\right]$ of $3.15 \mathrm{mg} / \mathrm{mL}$. After 5 minutes of mixing, the vial was centrifuged to isolate the precipitate. Under these conditions, $99.4 \%$ of the Tc-99 was isolated with the precipitate. After decanting the solutions, the $\left[\mathrm{Fe}(\mathrm{OH})_{\mathrm{x}}(\mathrm{Tc}-\mathrm{IV})\right]$ precipitates remained in open vials for 15 hours. Next, $30 \mathrm{~mL}$ of distilled water were introduced into one of the vials, and $30 \mathrm{~mL}$ of the Tc-99 free simulant were introduced into the other vial. After capping, the vials were continuously shaken, and aliquots were taken after 1, 5, and 11 days, centrifuged, filtered and analyzed to determine the amount of soluble pertechnetate.

Grout Samples To prepare samples, the premix components were mixed with appropriate amounts of the simulant or the slurry produced by first adding $\mathrm{FeSO}_{4}$. After 5 minutes of mixing, the fresh grout was poured into cylindrical molds ( $4 \mathrm{~cm}$ by $2 \mathrm{~cm}$ in diameter). The water/premix mass ratio was maintained between 0.4-0.5. Samples 1-4 were loosely covered with lids, while samples $4^{*}$ and 5 were sealed and not exposed to air. Table 2-2 presents data on the compositions of Samples 1-5.

Table 2-2 Grout compositions of the Samples 1 through 5

\begin{tabular}{|c|c|c|c|c|c|c|}
\hline \multirow{2}{*}{\multicolumn{2}{|c|}{ Components }} & \multicolumn{5}{|c|}{ Sample Number } \\
\hline & & 1 & 2 & 3 & $4 ; 4^{*}$ & 5 \\
\hline \multirow[b]{2}{*}{$\begin{array}{l}\text { Liquid } \\
\text { phase }\end{array}$} & \begin{tabular}{|l|} 
Simulant with Tc-99 \\
\end{tabular} & $\bar{X}$ & $\bar{X}$ & $\overline{-1}$ & $\overline{-1}$ & $\bar{X}$ \\
\hline & $\begin{array}{l}\text { Simulant with Tc-99 treated with } \\
\mathrm{FeSO}_{4}\left(\left[\mathrm{Fe}^{+2}\right]=2 \mathrm{~g} / \mathrm{L}\right)\end{array}$ & - & - & $X$ & $\mathrm{X}$ & - \\
\hline \multirow{3}{*}{$\begin{array}{l}\text { Solid } \\
\text { phase }\end{array}$} & PC & $\mathrm{X}$ & - & $\mathrm{X}$ & - & - \\
\hline & PC:BFS = (25:75), wt. $\%$ & - & $\mathrm{X}$ & - & $\mathrm{X}$ & - \\
\hline & PC:BFS:MP= $(25: 70: 5)$, wt. $\%$ & - & - & - & - & $\mathrm{X}$ \\
\hline
\end{tabular}

\subsection{Results}

ANSI/ANS 16.1 Monolithic Leaching Results The leaching tests from the monolith samples demonstrated that very little Tc-99 was released from the grout samples containing blast furnace slag from Holcim in the United States (same source of blast furnace slag used at Saltstone). Sample 5 used the Tc-99 simulant directly without pretreatment. The values for the effective diffusivity and leaching index for sample 5 are: 


\begin{tabular}{|c|c|}
\hline PROPERTY & SAMPLE \# 5 \\
\hline & \\
\hline Effective Diffusivity $\left(\mathrm{cm}^{2} / \mathrm{sec}\right)$ & $4.75 \mathrm{E}-12$ \\
\hline & \\
\hline Tc-99 Leaching Index & 11.4 \\
\hline
\end{tabular}

Due to variation in the Tc-99 results at these very low concentrations, the uncertainty interval for these properties most likely covers several orders of magnitude. Nevertheless, the measured values for both properties are within the intervals determined by Harbour et al [8] for similar grout formulations that used a waste stream much less concentrated in salt. The important conclusion is that, even with this very high salt solution (sodium concentration of $4.93 \mathrm{M}$ ), the blast furnace slag is able to reduce the Tc-99 to the immobile Tc(IV) state.

Pretreatment with $\mathrm{Fe}(+2)$ and $\mathrm{Fe}(+3)$ It has been shown that hydroxide precipitates, such as $\mathrm{Fe}(\mathrm{OH})_{\mathrm{x}}$, are effective for co-precipitating Tc-99 as $\mathrm{TcO}_{2} 2 \mathrm{H}_{2} \mathrm{O}$ under reducing conditions [11], [12], [13], [14] and [15]. Therefore, a series of experiments were performed to determine the reduction/immobilization of $\mathrm{Tc}(\mathrm{VII})$ by addition of $\mathrm{Fe}(\mathrm{II})$ and/or Fe(III). Table 2-3 shows the results including the Tc-99 distribution coefficients $\left(\mathrm{K}_{\mathrm{d}}, \mathrm{cm}^{3} / \mathrm{g}\right)$ calculated as the ratio of the Tc99 concentration in $1 \mathrm{~g} \mathrm{Fe}(\mathrm{OH})_{\mathrm{x}}$ to its residual concentration in $1 \mathrm{~mL}$ of the solution.

Table 2-3 Tc-99 Co-Precipitation from the doped simulant onto $\mathrm{Fe}(\mathrm{OH})_{\mathrm{x}}$.

\begin{tabular}{|c|c|c|c|c|c|c|c|c|c|}
\hline \multirow{3}{*}{$\begin{array}{c}\text { Sample } \\
\\
1\end{array}$} & \multirow{2}{*}{\multicolumn{2}{|c|}{$\begin{array}{c}\text { Carrier, } \\
\mathrm{g} / \mathrm{L}\end{array}$}} & \multirow{2}{*}{\multicolumn{2}{|c|}{$\begin{array}{l}\text { Precipitating } \\
\text { agent, } \\
\text { g/L }\end{array}$}} & \multicolumn{2}{|c|}{ After sorption } & \multicolumn{2}{|c|}{$\begin{array}{c}\text { Tc-99 Concentration in } \\
\text { BWS }\end{array}$} & \multirow{3}{*}{$\begin{array}{c}\begin{array}{c}\mathrm{K}_{\mathrm{d}}, \\
\mathrm{cm}^{3} / \mathrm{g}\end{array} \\
69\end{array}$} \\
\hline & & & & & \multirow{2}{*}{$\begin{array}{l}E_{h}, V \\
0.064\end{array}$} & \multirow{2}{*}{$\begin{array}{c}\mathrm{pH} \\
12.31\end{array}$} & \multirow{2}{*}{$\begin{array}{c}\begin{array}{c}\text { Prior to } \\
\text { sorption, } \\
\mathrm{Bq} / \mathrm{ml}\end{array} \\
637.4 \\
\end{array}$} & \multirow{2}{*}{$\begin{array}{c}\begin{array}{c}\text { After } \\
\text { sorption, } \\
\mathrm{Bq} / \mathrm{ml}\end{array} \\
560.3\end{array}$} & \\
\hline & $\mathrm{Fe}^{+3}$ & 1.00 & - & - & & & & & \\
\hline 2 & $\mathrm{Fe}^{3+}$ & 1.07 & $\mathrm{Fe}^{2+}$ & 1.05 & 0.042 & 12.60 & 589.3 & 96.4 & 1279 \\
\hline 3 & $\mathrm{Fe}^{3+}$ & 1.21 & $\mathrm{Fe}^{2+}$ & 2.10 & 0.061 & 12.37 & 707.7 & 91.2 & 1070 \\
\hline 4 & - & - & $\mathrm{Fe}^{2+}$ & 1.05 & 0.040 & 12.45 & 589.3 & 90.2 & 2771 \\
\hline 5 & - & - & $\mathrm{Fe}^{2+}$ & 2.10 & 0.033 & 12.50 & 707.7 & 50.5 & 2170 \\
\hline
\end{tabular}

The highest $\mathrm{K}_{d}$ values for Tc were obtained using ferrous sulfate (see Table 2-3). This leads to a precipitate that contains the reduced pertechnetate. Figure 2-1 shows the dependence of Tc-99 equilibrium concentrations in the solid precipitate and in solution. This linear dependence corresponds to $\mathrm{K}_{\mathrm{d}}=2200 \mathrm{~cm}^{3} / \mathrm{g}$ indicating that practically all of the Tc is present in the precipitate. 


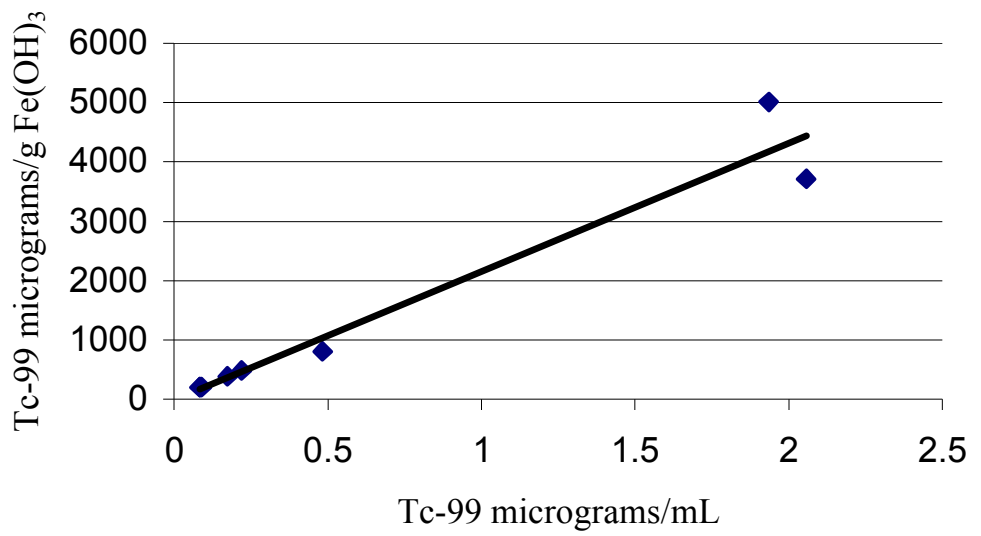

Figure 2-1 Tc-99 distribution between the solution and the solid phase

The stability of the precipitated $\left[\mathrm{Fe}(\mathrm{OH})_{\mathrm{x}} \mathrm{Tc}(\mathrm{IV})\right]$ system to re-oxidation under aerobic conditions was determined as described in the Experimental Section. The results are provided in Table 2-4.

Table 2-4 Tc-99 oxidation and desorption under aerobic conditions.

\begin{tabular}{|c||c|c|c||}
\hline \multirow{2}{*}{\multicolumn{1}{|c||}{ Leaching }} & \multicolumn{3}{c||}{$\%$ of sorbed Tc-99 released to solution } \\
\cline { 2 - 4 } & Day 1 & Day 5 & Day 11 \\
\hline Distilled water & 0.25 & - & 2.1 \\
\hline Simulant & 1.85 & 16.1 & 32.2 \\
\hline
\end{tabular}

In the presence of oxygen, re-oxidation and dissolution Tc(IV) occurs, with a color change from green that is characteristic of $\mathrm{Fe}(\mathrm{OH})_{2}$, to black and then to reddish brown that is characteristic of $\mathrm{Fe}(\mathrm{OH})_{3}$. Therefore, the pretreatment process with $\mathrm{Fe}(\mathrm{II})$ does not result in the irreversible production of $\mathrm{Tc}(\mathrm{IV})$. As is the case with blast furnace slag, the oxidation reduction process is reversible between $\mathrm{Tc}(\mathrm{IV})$ and $\mathrm{Tc}(\mathrm{VII})$.

Crushed Leaching Tests After 28 days of curing, samples 1-4 were leached using a modified ASTM D-5233 protocol [16] in which the grout was crushed to less than $2 \mathrm{~mm}$ in size with a mass ratio of water to solids of 10. Figure 2-2 shows the Tc-99 leaching results over 27 days. 


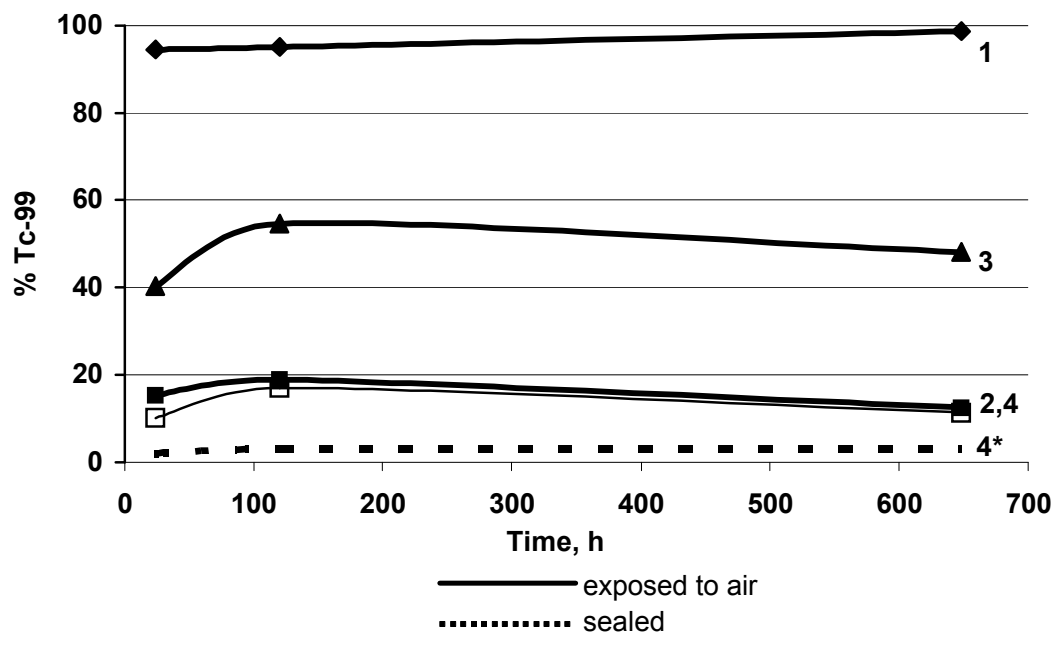

Figure 2-2 Percent of Tc-99 leached from crushed grout samples as a function of time. (Numbers next to the curves correspond to the sample numbers in Table 2-3.)

The crushed grout tests reveal important points. First, sample \#1, with no blast furnace slag, retains essentially none of the technetium. The pertechnetate does not encounter any reductants in the grout mix and is therefore sufficiently mobile within the pore volume to diffuse to the surface and into the surrounding liquid phase. This is consistent with the Performance Assessment where there is no credit taken for sorption of the pertechnetate within the grout matrix.

Sample \#3 also does not contain any blast furnace slag but has been reduced by the addition of ferrous sulfate. The precipitate which is formed (containing the technetium) is dispersed into the grout mix during blending. Approximately one-half of Tc-99 in the grout is released demonstrating that pretreatment does indeed retard the release of Tc-99 from the cured grout sample.

Samples \#2 and \#4 both contain blast furnace slag as part of the cementitious material mix. Sample \#2 was made using the simulant only whereas sample \#4 was made using the pretreated simulant. Both samples released Tc-99 to essentially the same level. This result demonstrates that blast furnace slag dominates the reduction of $\mathrm{Tc}(\mathrm{VII})$ in the salt solution with this formulation.

The fact that 15 to $20 \%$ of the Tc-99 is released in the presence of blast furnace slag is due to residual oxygen within the system. This fact was demonstrated by making an equivalent Sample \#4 (shown as $4 *$ in Figure 3 ) and excluding oxygen by capping the system. The leaching results show that only a very small amount of Tc-99 is released. The observation of a very small release of Tc-99 for Sample \#4* is most likely due to incomplete removal of all of the oxygen. 


\subsection{Conclusions}

A salt solution (doped with Tc-99), that simulates the salt waste stream to be processed at the Saltstone Production Facility, was immobilized in grout waste forms with and without (1) ground granulated blast furnace slag and (2) pretreatment with iron salts. The degree of immobilization of Tc-99 was measured through monolithic and crushed grout leaching tests. An effective diffusion coefficient of $4.75 \times 10^{-12}$ (Leach Index of 11.4) was measured using the ANSI/ANS16.1 protocol for the simulant containing pertechnetate. The leaching results show that, even in the presence of a concentrated salt solution (in this case with a sodium Molarity of 4.9), blast furnace slag can effectively reduce pertechnetate to the immobile (IV) oxidation state. Although Fe (II) was shown to be effective in reducing Tc-99 to the (IV) state, the strong reducing nature of the blast furnace slag present in the grout formulation dominated the reduction of Tc-99 in the cured grouts. Finally it was confirmed that leaching only occurs if there is oxygen present to oxidize the Tc (IV) to the pertechnetate state.

\subsection{FINAL STATUS SE-79 LEACHING FROM SALTSTONE}

\subsection{Objective}

The objective of this task was to determine the degree of sorption (i.e., retention) of soluble selenium ions (originally present in the salt waste stream) within the cured Saltstone. The approach was to measure the leaching of selenium from both monolithic and crushed Saltstone samples. In addition a determination of the role of reductant in the Saltstone (present in slag) in this sorption process (reducing selenate $\left(\mathrm{SeO}_{4}{ }^{-2}\right)$ to selenite $\left(\mathrm{SeO}_{3}{ }^{-2}\right)$ will be made by performing the leaching experiments in the presence of either inert and oxygen enriched gases.

The intent was to look at two bounding concentrations of selenium in the salt solution (with and without oxygen) to determine the leaching performance as a function of selenium ion concentration and redox state of the selenium. However, funding was provided for only one bounding level which turned out to be the highest level of selenium $\left(\sim 5 \times 10^{-3} \mathrm{M}\right)$ and the oxygen dependence of this leaching could not be completed 


\subsection{Background}

Selenium-79 (Se-79) was produced as a fission product within the SRS reactors with a yield of $0.04 \%$ and is present in the salt waste stream after processing of the spent fuel and target assemblies.

The performance assessment of Saltstone relies on models to calculate the dose at the point of compliance for all radionuclides originally present in the waste stream that are incorporated within Saltstone. Tc-99 is the most important radionuclide in Saltstone and a discussion of this isotope was provided in Section 2.0. Another radionuclide identified as important by those who perform the Performance Assessment is Se-79. This isotope is a beta emitter, has a half-life of 650,000 years, and therefore contributes to the dose at the point of compliance over the 10,000 year compliance period.

It is important to determine the $\mathrm{K}_{\mathrm{d}}$ and diffusivity of Se-79 for inclusion into the model that calculates release rates and transport through the Vadose Zone and eventually to the point of compliance. With these parameters and an understanding of the role of redox in retention, a more realistic time dependence for the Se-79 release from Saltstone vaults into the environment can be calculated. It also provides the opportunity for taking credit for sorption of Se-79 and the consequent retardation of Se-79 release into the environment.

Projections of upcoming salt batches that will be processed into Saltstone indicate that selenium will be present as a soluble salt at concentrations from $1 \times 10^{-5} \mathrm{M}$ up to $1 \times 10^{-3} \mathrm{M}$. On the other hand, the concentration of Se-79 has a maximum projected value of $7 \times 10^{-7}$ Curies/gallon. For a specific activity of $0.07 \mathrm{Ci} / \mathrm{g}$, this translates into a concentration of Se-79 of 2.6 micrograms/liter $\left(3.2 \times 10^{-8} \mathrm{M}\right)$. Therefore the sorption testing was planned over a range of non-radioactive (natural) selenium from ( 800 to 80,000 micrograms/L). The major isotope of natural selenium is Se-80 comprising approximately half of the natural selenium. Because the sorption should be relatively insensitive to the isotope of selenium involved, it is assumed that the sorption of Se-79 will be equivalent to that determined for the non-radioactive Se- 80 .

Selenium exists in four oxidation states: selenide $(-2)$, selenium $(0)$, selenite $(+4)$ and selenate $(+6)$. Both selenite $\left(\mathrm{SeO}_{3}{ }^{-2}\right)$ and selenate $\left(\mathrm{SeO}_{4}{ }^{-2}\right)$ are expected to be present in the pore spaces of ordinary Portland cement with the ratio dependent on the redox state of the mix[17]. The Saltstone Premix contains $45 \mathrm{wt} \%$ of ground granulated blast furnace slag which has reductive capacity (e.g., reduces Tc $(+6)$ to Tc $(+4)$ as described in Section 1). It has been proposed that the +4 oxidation state of selenium is more tightly bound to cement based concretes. However, no studies have been conducted for salt solutions containing reducing slag. Therefore, this task was designed to measure the differences in sorption between the +4 and +6 oxidation states. This can be accomplished by performing the tests as a function of slag concentration and by controlling the oxygen content in the salt solution. 


\subsection{Experimental}

Selenium concentrations in the solutions were measured by ICP-MS (Agilent 7500C). The sensitivity of the method is $0.001 \mathrm{mg} / \mathrm{L}$ with a measurement uncertainty is $5 \%$.

An MCU simulant was used as the salt solution that was mixed with the normal premix materials (fly ash: blast furnace slag: portland cement at 45:45:10 mass ratio). The water/premix mass ratio was 0.6 with a mixing time of approximately one hour. The samples were cured in sealed containers for $\sim 90$ days prior to testing.

The same protocols used for the Tc-99 leaching experiments were used for the selenium leaching tests. These included a crushed sample (ASTM D-5233) leaching protocol and a monolithic sample (ANSI/ANS 16.1) leaching protocol. As discussed in the Objectives Section, only the highest level of selenium was tested.

\subsection{Results and Discussion}

The leaching results for the crushed sample revealed that most of the selenium is released from the grout within 28 days. The percent of selenium released from the crushed grout for the three sampling times are:

\begin{tabular}{|c|c|}
\hline TIME & SELENIUM RELEASED \\
\hline days & percent \\
\hline & \\
\hline 1 & 73 \\
\hline 7 & 80 \\
\hline 28 & 84 \\
\hline
\end{tabular}

Oxygen was not excluded from these solutions during the leaching period. The experiments with inert gas purging were not performed which would tell whether redox level plays any role in selenium release from the grout. (E.g. with Tc-99 leaching, removal of oxygen prevents any leaching of Tc-99 into the solution).

In this regard it is informative to compare the concentration of selenium in the grout with the concentration of reductant in the grout (from the blast furnace slag). Holcim blast furnace slag from the US was used in these tests, and it has previously been demonstrated that this slag contains 0.8 milliequivalents of electrons per gram. On a mass basis, the slag was present at $24.0 \%$ relative to the cured grout leading to a value of 0.2 milliequivalents of electrons per gram of cured grout. This can be compared to the concentration of selenium in the grout of $2.2 \times 10^{-3}$ milliequivalents per gram of cured grout. These numbers reveal that initially, there are 100 times 
more electrons (reductants) than selenium ions in the grout. However, not all of these reductants may be accessible until all of the slag has reacted.

The ANSI/ANS 16.1 leaching tests provided a value for the effective diffusivity of $\sim 5 \times 10^{-9}$ $\mathrm{cm}^{2} / \mathrm{sec}$ and leaching index for selenium of $\sim 8.2$.

\begin{tabular}{|c|c|}
\hline PROPERTY & SAMPLE \# 5 \\
\hline & \\
\hline Effective Diffusivity $\left(\mathrm{cm}^{2} / \mathrm{sec}\right)$ & $4.75 \mathrm{E}-12$ \\
\hline & \\
\hline Tc-99 Leaching Index & 11.4 \\
\hline
\end{tabular}

\subsection{Conclusions}

These initial leaching results for selenium indicate, that at very high concentrations of selenium in the salt solution, release of selenium is quite high for the accelerated crushed sample tests in the presence of oxygen. On the other hand, conservative values for the diffusivity and leach index for selenium have been determined.

Additional leach testing at the low bounding level of selenium in the salt solutions with and without oxygen are required to better assess the retention of selenium in this grout formulation.

\subsection{FINAL STATUS OF HEAT OF HYDRATION FOR SALTSTONE}

\subsection{Objective}

The objective of this task is to develop Saltstone mixes with an overall heat of hydration that is reduced relative to current design mixes. Specifically, the objective is to achieve a reduction in heat generation through partial or complete substitution of inert materials (or materials having reduced hydraulic or pozzolanic activities) for the fly ash and/or the blast furnace slag. The resultant mixes with lower heat of hydration must also have fresh and cured grout properties that meet the Saltstone specifications.

\subsection{Background}

The hydration reactions of cementitious materials are exothermic and therefore generate heat. This heat of hydration can be dissipated for most grout or concrete placements due to effective 
heat exchange with the air in contact with the surface of the concrete. Concrete placement for pavement is an example where the heat generation is not critical due to the relatively thin layer of placement. However, as the minimum dimension of a placement approaches $\sim 3$ feet, heat dissipation becomes more difficult and significant increases in temperature as well as temperature differences within the concrete can occur. (Temperature gradients within the concrete during curing can lead to thermal cracking of the concrete or grout.) Placements where temperature impacts must be considered and mitigated are referred to in the industry as "mass concrete" placements. For example, a large mat foundation with a thickness greater than 3 feet is referred to as a mass concrete placement.

In addition to this dimensional definition of mass concrete, it is also important to consider the cementitious materials content of the mix. In this regard, it has been proposed that the $3 \mathrm{ft}$. definition of mass concrete be expanded to specify that the mixes contain at least $564 \mathrm{lbs} / \mathrm{yd}^{3}$ $\left(335 \mathrm{~kg} / \mathrm{m}^{3}\right)$ of cementitious materials.

Table 4-1 provides the amounts of cementitious materials (in concentration units of $1 \mathrm{bs} / \mathrm{yd}^{3}$ ) for baseline compositions using both ARP/MCU and DDA waste streams at a water to premix ratio of 0.60 . The actual amounts of cementitious materials significantly exceed the $564 \mathrm{lbs} / \mathrm{yd}^{3}$ value used in the definition. An alternative approach, known as Schmidt's method [18] reduces the amount of fly ash and slag by $50 \%$ due to the fact that these materials often do not produce as much heat (i.e., are less reactive) as Type I/II portland cement.

Saltstone placement within the new vaults in general fits the mass concrete definition. Although, placement for a 1 day pour ( 8 hours) at Saltstone leads to height of only $0.65 \mathrm{ft}$, subsequent placements made on following days result in overall placements greater than 3 feet. In addition, the cementitious content of the mix is considerably higher than $564 \mathrm{lbs} / \mathrm{yd}^{3}$. For these reasons, Saltstone can be considered as a mass concrete placement requiring strategies to mitigate the overall temperature rise and temperature differentials within the vaults.

It is important to note that Schmidt's method [18] applies to mixes made with water whereas the Saltstone mixes contain significant amounts of base and salts that can activate and accelerate the hydraulic/pozzolanic reactions of slag and fly ash.

Table 4-1 Cementitious content of MCU and DDA mixes at a water to premix ratio of 0.60.

\begin{tabular}{|r|c|c|c|c|}
\hline Cementitious Material & \multicolumn{2}{|c|}{ Actual Amounts } & \multicolumn{2}{c|}{ Schmidt's Method } \\
\hline & MCU Simulant & DDA Simulant & MCU Simulant & DDA Simulant \\
\hline & lbs/yd $^{\mathbf{3}}$ & Ibs/yd $^{\mathbf{3}}$ & lbs/yd $^{\mathbf{3}}$ & lbs/yd $^{\mathbf{3}}$ \\
\hline portland cement & 157.1 & 162.9 & 157.1 & 162.9 \\
\hline Class F fly ash & 706.8 & 733.1 & 353.4 & 366.6 \\
\hline blast furnace slag & 706.8 & 733.1 & 353.4 & 366.6 \\
\hline Total & $\mathbf{1 5 7 0 . 7}$ & $\mathbf{1 6 2 9 . 1}$ & $\mathbf{8 6 3 . 9}$ & $\mathbf{8 9 6 . 0}$ \\
\hline
\end{tabular}


The consequences of not controlling the temperature of Saltstone during curing are:

1. Thermal cracking. Cracking can lead to increased surface area and increased hydraulic conductivity of the Saltstone. In turn this can increase oxygen diffusion, consequent oxidation of reduced Tc $(+4)$ to a mobile form called pertechnetate, leaching and lead to enhanced degradation through such mechanisms as delayed ettringite formation. These effects will change the assumptions used in the Performance Assessment, which calculates potential doses to future inhabitants out to 10,000 years.

2. Higher volatility of organic impurities (such as Isopar used in the caustic side solvent extraction). It has been shown that higher temperatures in Saltstone increase the volatility of organics such as Isopar and benzene. The temperature limits of Saltstone will determine whether or not active ventilation will be required.

3. Constraints on processing rates. Processing of Saltstone is dependent on the heat of hydration of the grout and consequent increases in the temperature of the mass concrete. Lowering the heat of hydration can enhance processing rates at the Saltstone Processing Facility.

This task was undertaken to address these consequences by attempting to lower the heat of hydration through substitution of inert or less reactive components in the mix.

The first stage of this task was to determine which calorimetric approach would provide the best data to determine whether a lower heat of hydration was achieved. Since an adiabatic calorimetric measurement of a Saltstone mix was performed in 1996 [19], it was decided to use isothermal calorimetry to monitor heat generation in Saltstone mixes. A comparison of results could then be made between isothermal and adiabatic calorimetry.

This first stage of the task also focused on substitution of a less reactive fly ash for the Class $\mathrm{F}$ fly ash used at Saltstone.

\subsection{Experimental}

The heat of hydration was measured using a differential diathermal microcalorimeter (Calvet type calorimeter) modified by Professor Yu.V. Kondratiev [20]. The BAPEK-1 model was fabricated at the Baltic Plant in 2003. A block diagram of the instrument is shown in Figure 4-1. 


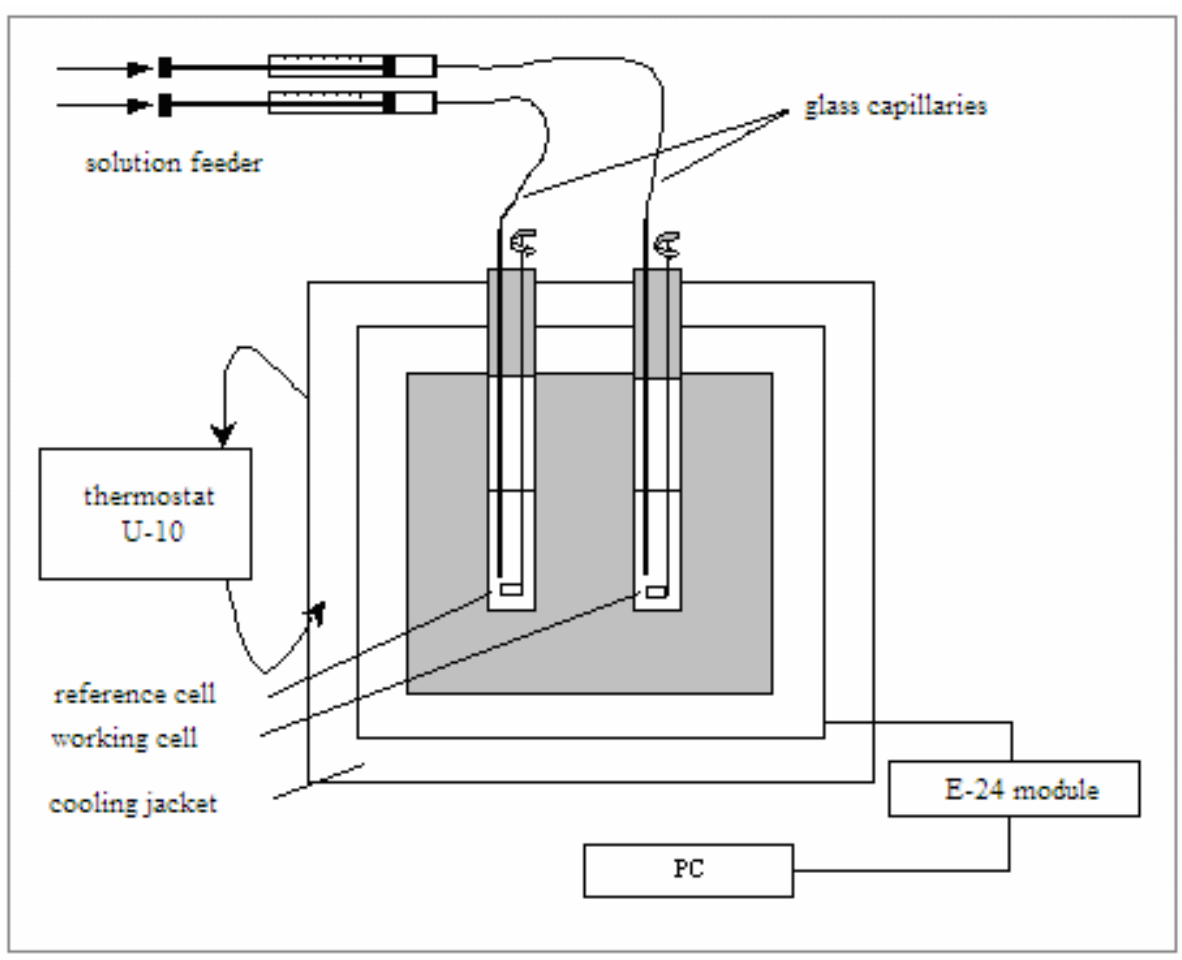

Figure 4-1 Block diagram of the isothermal calorimeter used in this task

The Figure above shows a block diagram of the differential diathermal (conductive walls) isothermal calorimeter that makes it possible to provide for both continuous and interrupted feed of a titrant. The E-24 module is an 8-channel A/D converter that records and digitizes the EMF in the electrical circuit. The module is designed to be connected to the PC.

The system was calibrated by placing a known amount of potassium chloride (heat of dissolution equal to $17.3 \mathrm{~kJ} / \mathrm{mole}$ ) into water and monitoring the voltage with time. As a result of this calibration, the voltage output can be converted to watts by multiplication by the conversion factor, K, of 5.92 watts/volt.

During calorimetric measurements, the simulant solution was added to the premix directly in the calorimeter and mixed with a mechanical stirrer. In all experiments, the temperature was $25.2 \pm$ $0.1^{\circ} \mathrm{C}$. The composition of the simulant solution is given in Table 4-2. 
Table 4-2 Simulant Solution Composition

\begin{tabular}{|c|c|}
\hline Component & Concentration, $\mathrm{M}$ \\
\hline $\mathrm{NaNO}_{3}$ & 0.650 \\
\hline $\mathrm{NaNO}_{2}$ & 0.100 \\
\hline $\mathrm{Na}_{2} \mathrm{SO}_{4}$ & 0.020 \\
\hline $\mathrm{NaOH}$ & 1.100 \\
\hline $\mathrm{Al}\left(\mathrm{NO}_{3}\right)_{3}$ & 0.050 \\
\hline $\mathrm{Na}_{2} \mathrm{CO}_{3}$ & 0.100 \\
\hline $\mathrm{Na}_{2} \mathrm{HPO}_{4}$ & 0.008 \\
\hline $\mathrm{NaCl}_{2}$ & 0.001 \\
\hline $\mathrm{Na}_{2} \mathrm{C}_{2} \mathrm{O}_{4}$ & 0.002 \\
\hline
\end{tabular}

In this series of experiments, the Class F fly ash was replaced partially or completely by a ferro-spinel fraction of Russian fly ash. The composition of the iron rich Russian fly ash, FA $(\mathrm{Fe})$, is provided in Table 4.3.

Table 4-3 Chemical Composition of Ferro-Spinel Fly Ash

\begin{tabular}{|c|c|c|c|c|c|c|c|c|c|c|}
\hline \multirow{2}{*}{ Fraction } & \multicolumn{10}{|c|}{ Content, \% } \\
\cline { 2 - 11 } & $\mathrm{SiO}_{2}$ & $\mathrm{Al}_{2} \mathrm{O}_{3}$ & $\mathrm{Fe}_{2} \mathrm{O}_{3}$ & $\mathrm{CaO}$ & $\mathrm{MgO}$ & $\mathrm{SO}_{3}$ & $\mathrm{P}_{2} \mathrm{O}_{5}$ & $\mathrm{~K}_{2} \mathrm{O}$ & $\mathrm{MnO}$ & $\sum$ \\
\hline & 6.9 & 2.9 & 83.6 & 8.6 & 2.0 & 1.4 & 0.07 & 0.07 & 0.2 & 105.74 \\
\hline
\end{tabular}

Table 4-4 provides mass ratios of the cement paste samples.

Table 4-4 Mass Ratios in Cement Paste Samples

\begin{tabular}{|c|c|c|c|c|c|c|}
\hline Mixture \# & Water/Premix & $\begin{array}{c}\text { Mass of } \\
\text { solution, g }\end{array}$ & $\begin{array}{c}\text { Mass of } \\
\text { OPC, g }\end{array}$ & $\begin{array}{c}\text { Mass of } \\
\text { BFS, g }\end{array}$ & $\begin{array}{c}\text { Mass of } \\
\text { FA, g }\end{array}$ & $\begin{array}{c}\text { Mass of } \\
\text { FA(Fe), g }\end{array}$ \\
\hline $1(\mathrm{a})$ & 0.60 & 6.0 & 0.88 & 3.96 & 3.96 & - \\
\hline $1(\mathrm{~b})$ & 0.55 & 6.0 & 0.96 & 4.32 & 4.32 & - \\
\hline 2 & 0.60 & 6.0 & 0.88 & 3.96 & 2.97 & 0.99 \\
\hline 3 & 0.60 & 6.0 & 0.88 & 3.96 & - & 3.96 \\
\hline
\end{tabular}




\subsection{Results}

The results of the isothermal measurements for the mixes in Table 4-4 are provided below.

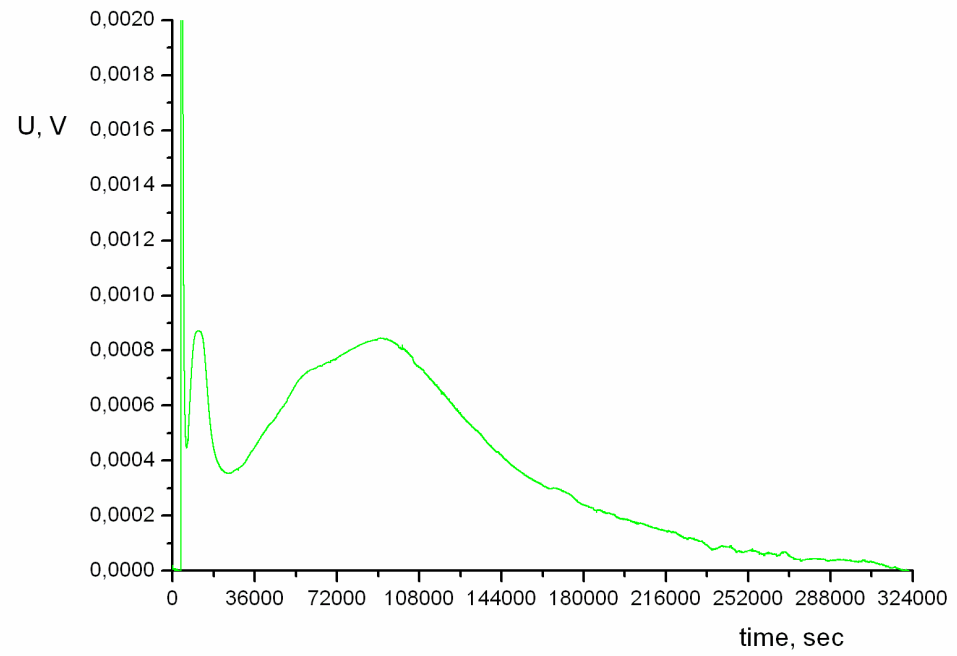

Figure 4-2 Calorimetric Curve of Cement Mixture \# 1(a) (Water/Premix=0.6). UV is volts.

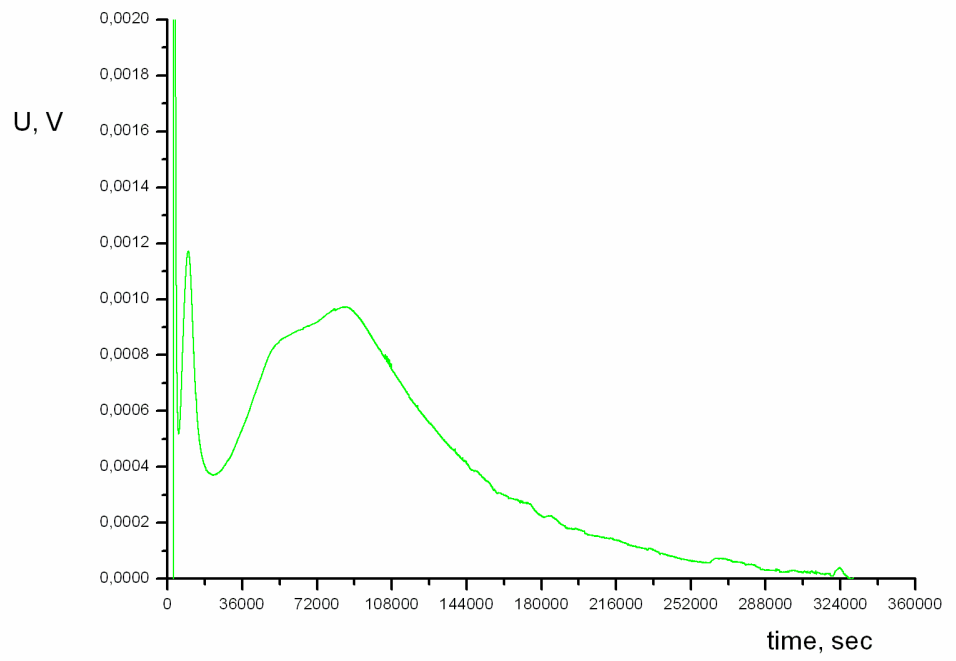

Figure 4-3 Calorimetric Curve of Cement Mixture \# 1(a) (Water/Premix=0.6). UV is volts. 
WSRC-STI-2007-00056

Rev. 0

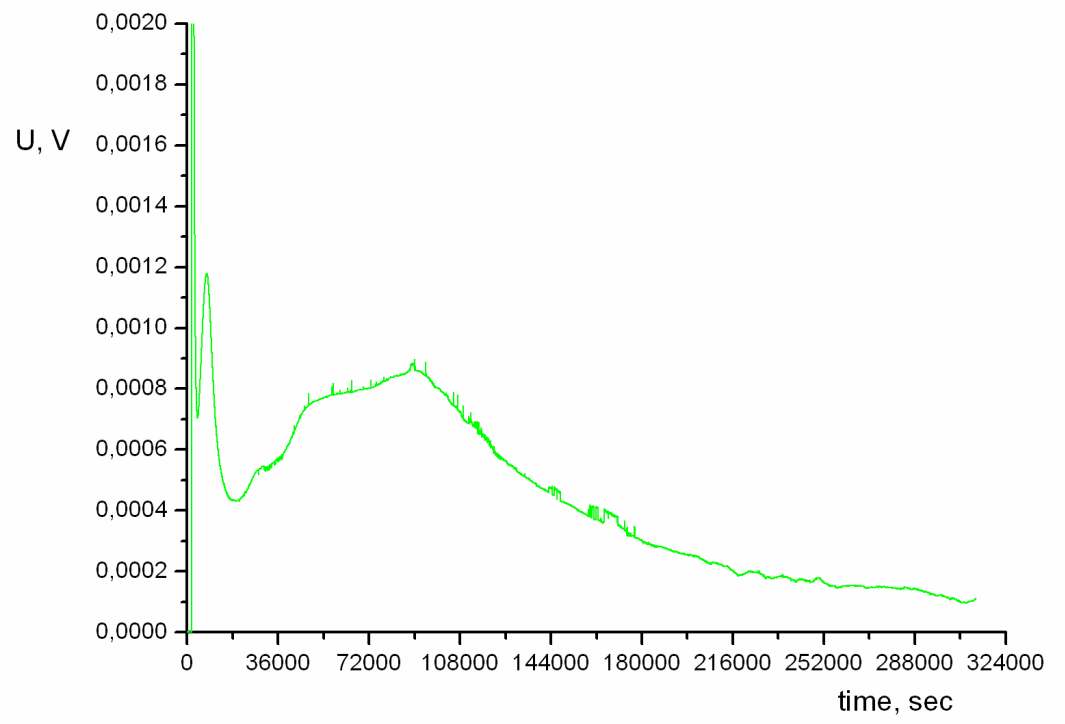

Figure 4-4 Calorimetric Curve of Cement Mixture \# 1(a) (Water/Premix=0.6). UV is volts.

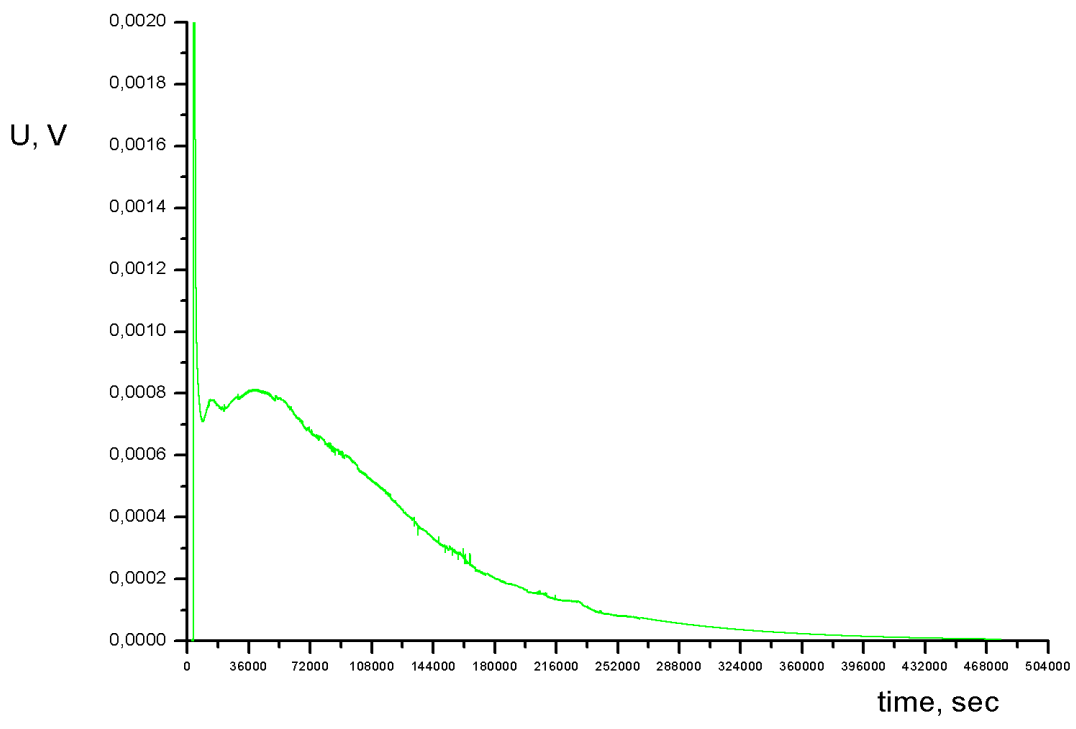

Figure 4-5 Calorimetric Curve of Cement Mixture \# 1(a) (Water/Premix=0.6). UV is volts. 
The data for the integrated heats of hydration for these samples are provided in Table 4-5. The data are given in units of $\mathrm{kJ} / \mathrm{kg}$ of grout and $\mathrm{kJ} / \mathrm{kg}$ of premix.

Table 4-5 Specific Heat Release in Various Cement Systems

\begin{tabular}{|c|c|c|c|}
\hline \multirow{2}{*}{ Water/Premix } & Premix & Heat of hydration $(\mathrm{kJ} / \mathrm{kg})$ & Heat of hydration $(\mathrm{kJ} / \mathrm{kg})$ \\
\hline & & Per kg of grout & Per kg of premix \\
\hline 0.60 & $1(\mathrm{a})$ & 48 & 81 \\
\hline 0.55 & $1(\mathrm{~b})$ & 45 & 73 \\
\hline 0.60 & 2 & 56 & 95 \\
\hline 0.60 & 3 & 48 & 81 \\
\hline
\end{tabular}




\subsection{Discussion}

Isothermal vs. Adiabatic Measurements Steimke and Fowley [19] measured the temperature increase of a Saltstone mix using adiabatic calorimetry. Their data, presented as the heat of hydration (watts/kg of grout), is provided in Figure 4-6 for reference.

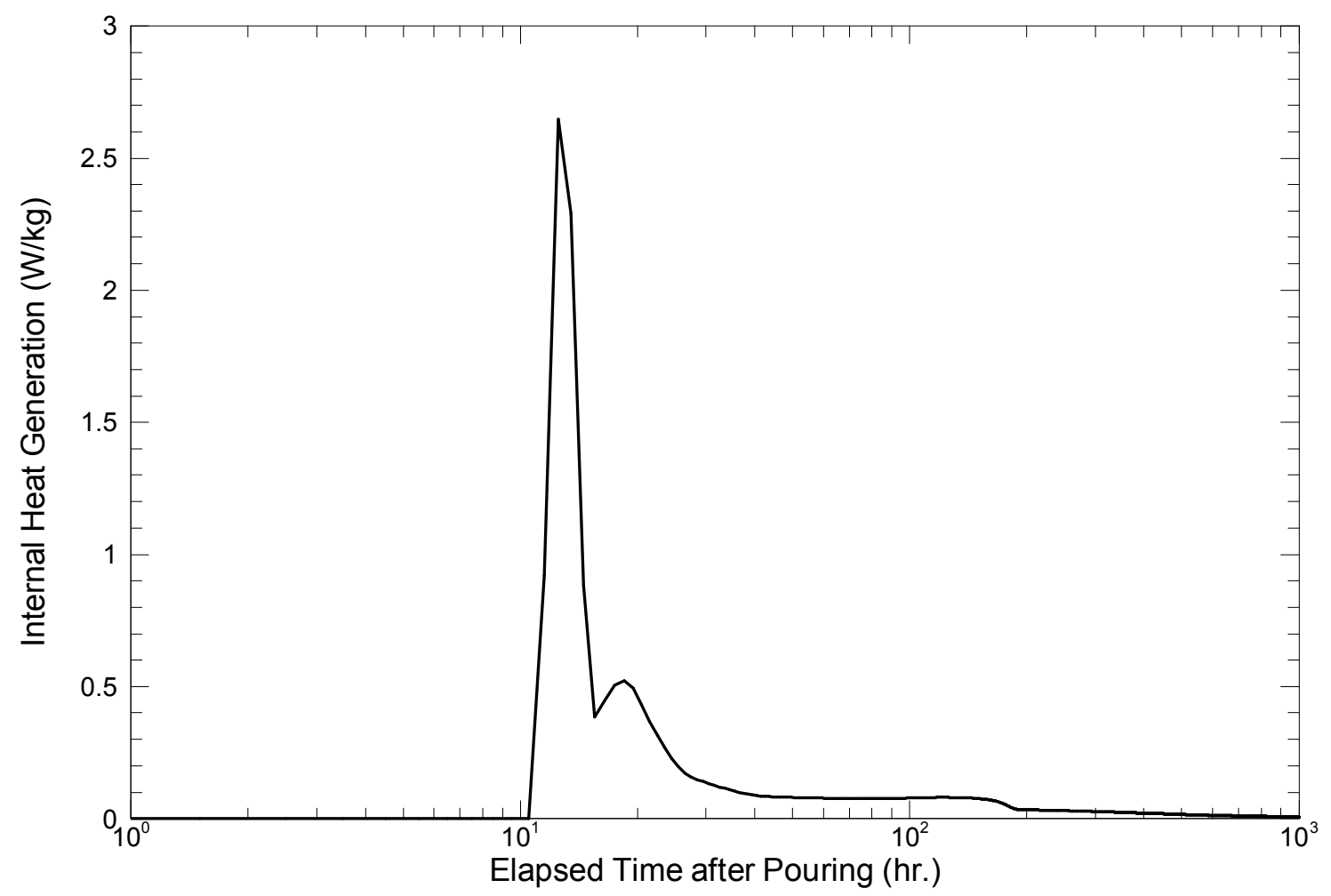

Figure 4-6 Heat generation for Saltstone as measured using adiabatic calorimetry [19]

Their data show a sharp peak starting at about 10 hours and a second peak with a maximum at 20 hours. No temperature rise was observed in the first 10 hours. The authors did not integrate the area under the curve to get the total heat of hydration per kilogram of Saltstone.

However, Steimke and Fowley [19] did measure the specific heat of Saltstone (0.34 calories/ gram) and from the temperature rise as a function of time it is possible to calculate the heat of hydration at any time. For example, after 80 hours, the temperature of the Saltstone had increased by $47^{\circ} \mathrm{C}$. Since the specific heat is 0.34 calories/gram, the heat released must be equal to 15.98 calories per gram. This is equivalent to $69 \mathrm{~kJ} / \mathrm{kg}$ of Saltstone and can be compared to $45-56 \mathrm{~kJ} / \mathrm{kg}$ measured isothermally as reported above.

It units of heat generated per kg of cementitious material, Steimke and Fowley's [19] adiabatic measurements gave $105 \mathrm{~kJ} / \mathrm{kg}$ compared to $73-95 \mathrm{~kJ} / \mathrm{kg}$ isothermally as determined in this study. 
The slightly higher values obtained adiabatically over this 80 hour time period most likely reflects the increased rate of hydration at higher temperatures in the adiabatic setup. For example the temperature of the mix was $\sim 70{ }^{\circ} \mathrm{C}$ after 20 hours in the adiabatic test compared to $25.2{ }^{\circ} \mathrm{C}$ in the isothermal test.

In the adiabatic measurements, the time of measurement covered 160 hours and the temperature reached $108{ }^{\circ} \mathrm{C}$, a temperature rise of $71{ }^{\circ} \mathrm{C}$. Therefore, over this time period, the heat generated was $101 \mathrm{~kJ} / \mathrm{kg}$ of grout and $187 \mathrm{~kJ} / \mathrm{kg}$ of cementitious materials. It appears that the temperatures would have been higher still if not for equipment problems in the adiabatic measurements.

The extent of hydration reactions can be estimated by these measurements. The theoretical amount of heat generated for cementitious materials can be as high as $418 \mathrm{~kJ} / \mathrm{kg}$ or reduced as in the Schmidt approach to $\sim 230 \mathrm{~kJ} / \mathrm{kg}$. Using the Schmidt method, the extent of reaction after 80 hours was $36 \%$ complete as determined by isothermal calorimetry and $46 \%$ complete as determined by adiabatic calorimetry. Using the theoretical maximum wherein the fly ash and slag are equivalent hydraulically to the portland cement, the extent of reaction after 80 hours is $20 \%$ complete by isothermal calorimetry and $25 \%$ complete by adiabatic calorimetry.

Degrees of reaction of portland cement and portland cement blended with reactive mineral admixtures (fly ash and slag) measured by Feng et al [21] provides a reference to the data presented above. Using a point counting procedure with scanning electron micrographs of grout samples cured as a function of time, these authors were able to measure the degree of reaction of not only portland cement but also slag and fly ash.

After 4 days of curing, a portland cement based mix showed that the hydration reactions of portland cement were $\sim 53 \%$ complete. For the blended cement pastes, the degree of hydration of portland cement was roughly the same as it was in the portland cement only paste. In contrast with the blended systems, slag was only $\sim 8 \%$ reacted after 4 days and only $30 \%$ reacted after 40 days. Class F fly ash was even less reactive in this system with only 1 to $2 \%$ of the fly ash hydrated after 4 days and $11 \%$ reacted after 28 days. These experiments were performed with pastes made of distilled water.

If one applies these reaction rates to the Saltstone system, then $10 \%$ of the premix will have reacted in 4 days. This translates to $\sim 40 \mathrm{~kJ} / \mathrm{kg}$, a value roughly half of what we observed isothermally.

\section{Fly Ash Replacement}

Although the degrees of reaction measured by Feng et al [21] were done in water rather than salt solution, the general trend of reactivities between portland cement, slag and fly ash are consistent with most other studies. That is, the rate of hydration follows the order from high rate to low rate of: portland cement, slag and fly ash. 
If only several percent of the fly ash reacted within the first four days, then the difference in heat generation between systems containing Class F fly ash and the Russian high iron fly ash would be lost in the noise of the measurement.

\subsection{Conclusions}

There was good agreement between the isothermal measurements of heat of hydration performed in this task with previous measurements of heat of hydration of Saltstone obtained adiabatically over the same 80 hour time period.

The slightly higher heat of hydration per gram of cementitious material measured adiabatically can be explained by the higher temperatures achieved during the adiabatic measurements. For example, the temperature of the mix had climbed to $\sim 70{ }^{\circ} \mathrm{C}$ after 20 hours adiabatically (as compared to the $25.2{ }^{\circ} \mathrm{C}$ temperature maintained isothermally). It is known that hydration reaction rates increase with increasing temperature which explains the discrepancy between the two methods.

The isothermal measurements reveal additional details of the heat generation process that were not evident in the adiabatic measurements. An initial heat release in the first minutes was observed isothermally. A second peak at about 5 hours was also observed isothermally that was not detected adiabatically. The major heat releases in the 10 to 30 hour period were observed by both techniques but at slightly different times and ratios of the two major peaks that comprise that region.

The extent of hydration reactions can be estimated by these measurements. The theoretical amount of heat generated for cementitious materials can be as high as $418 \mathrm{~kJ} / \mathrm{kg}$ or reduced as in the Schmidt approach to $\sim 230 \mathrm{~kJ} / \mathrm{kg}$. Using the Schmidt method, the extent of reaction after 80 hours was $36 \%$ complete as determined by isothermal calorimetry and $46 \%$ complete as determined by adiabatic calorimetry. Using the theoretical maximum wherein the fly ash and slag are equivalent hydraulically to the portland cement, the extent of reaction after 80 hours is $20 \%$ complete by isothermal calorimetry and $25 \%$ complete by adiabatic calorimetry.

If one applies these reaction rates observed by Feng et al to the Saltstone system, then $10 \%$ of the premix will have reacted in 4 days. This translates to $\sim 40 \mathrm{~kJ} / \mathrm{kg}$, a value roughly half of what we observed isothermally.

\subsection{FINAL STATUS OF PORFLOW ${ }^{\mathrm{TM}}$ MODELING}

\subsection{Objective}

The objective of this task was to incorporate the experimental results on Tc-99 and Se-79

leaching into the PORFLOW ${ }^{\mathrm{TM}}$ model and determine the release of these radionuclides from the 
vault over the 10,000 year regulatory period. In addition, the sensitivity of the release of these radionuclides to variations in hydraulic conductivity and effective diffusivity was investigated.

\subsection{Background}

The PORFLOW ${ }^{\mathrm{TM}}$ flow and transport model is currently being used in support of the Performance Assessment for Saltstone at Savannah Rive Site.

An application of this model to oxygen infiltration into Saltstone was performed by Kaplan and Hang [22]. Their report details the method and model.

The effective diffusivity for Tc-99, determined experimentally as part of this overall program was used as input to PORFLOW ${ }^{\mathrm{TM}}$. However, the funding for the selenium work was halted part way through that task and therefore, the determination and input of the selenium diffusivity was not accomplished. Therefore, the results reported here use only data on Tc-99.

\subsection{Results and Discussion:}

The first task was to reproduce the results of Kaplan and Hang [22]. Using the inputs that Kaplan and Hang [22] used in their work, Sergei Chivilikin was able to completely reproduce the oxygen infiltration rates into the Saltstone presented in the report. This required several iterations with Thong Hang and was an essential prerequisite of this task to ensure that both groups were modeling equivalently with PORFLOW ${ }^{\mathrm{TM}}$. The results of the modeling calculations are provided in Figure 5-1. 


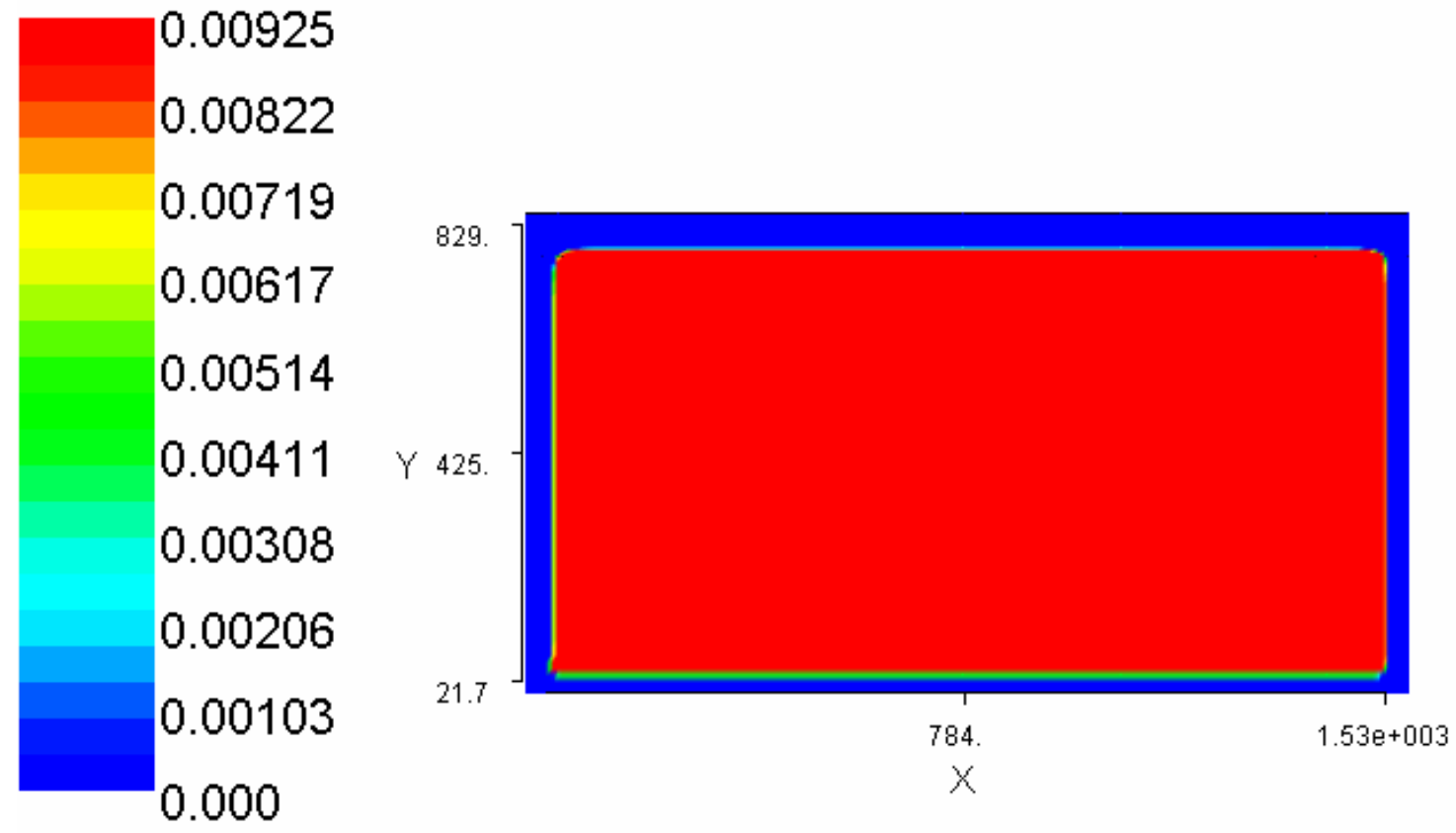

Figure 5-1 Meq e-/g solid after 250,000 Years. The $\mathrm{X}$ axis in the horizontal distance of the vault in $\mathrm{cm}$ and $\mathrm{Y}$ axis is the vertical distance of the vault in $\mathrm{cm}$. Red indicates no oxidation whereas blue indicates full oxidation of the slag by oxygen.

\section{Sensitivity Analyses}

A number of calculations were performed to assess the sensitivity of the release of Tc-99 from the vault. These examples demonstrate that significant release can occur over the 10,000 year period provided that the hydraulic conductivity and effective diffusivities have both increased over the initial values. This could happen if the Saltstone and concrete walls of the vault deteriorate with time.

For example, assuming that the effective diffusivities for the Saltstone and concrete are equal to $10^{-6} \mathrm{~cm}^{2} / \mathrm{sec}$, the release of Tc-99 depends on the hydraulic conductivity as shown in Figure 5-2. 
Rev. 0

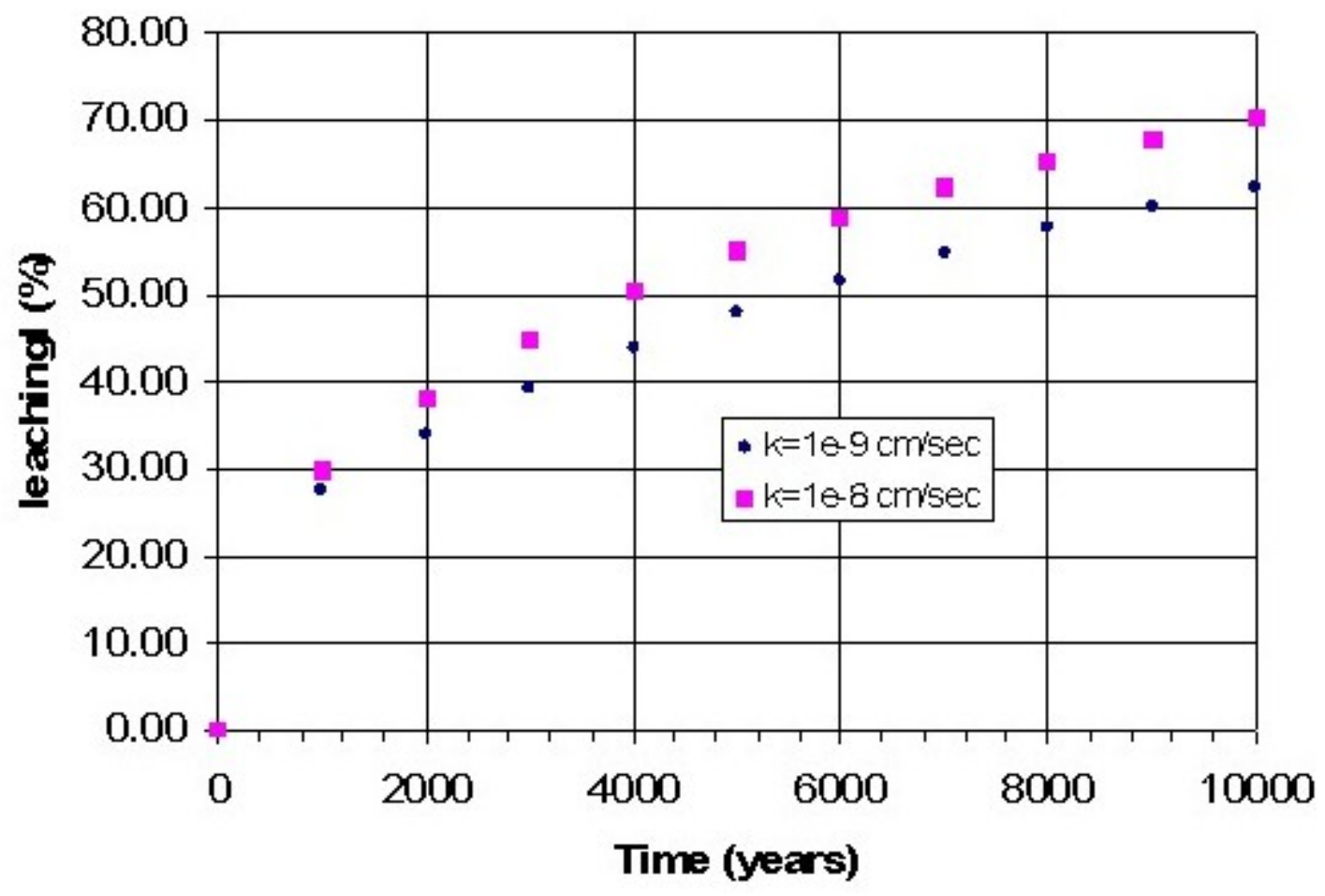

Figure 5-2 Percent of Tc-99 leached from Saltstone at two values of Hydraulic Conductivity (k) as shown in the Figure.

Another example of sensitivity is shown in Figure 5-3. In this case the hydraulic conductivity was selected at $10^{-8} \mathrm{~cm} / \mathrm{sec}$ and the diffusivity varied over three orders of magnitude. In this case, the release of Tc-99 is relatively insensitive to changes in diffusivity at these values. 
WSRC-STI-2007-00056

Rev. 0

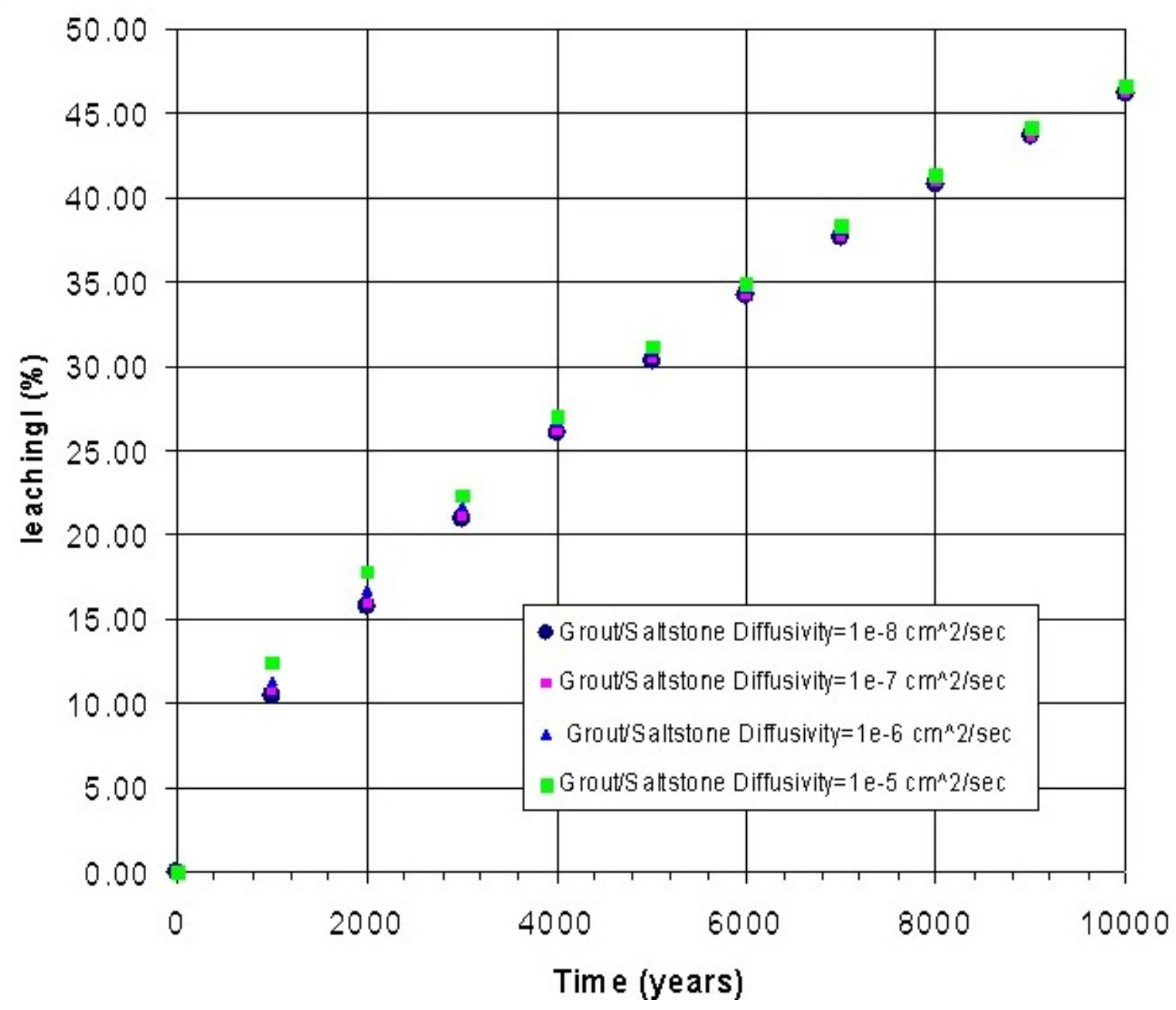

Figure 5-3 Percent of Tc-99 released from the vault as a function of Saltstone diffusivity. The Vault Concrete Diffusivity was set equal to $10^{-8} \mathrm{~cm}^{2} / \mathrm{sec}$ for these calculations.

Again for a hydraulic conductivity of $10^{-8} \mathrm{~cm} / \mathrm{sec}$, the sensitivity to Tc-99 release to changes in both vault concrete and Saltstone diffusivity is provided in Figure 5-4. 
WSRC-STI-2007-00056

Rev. 0

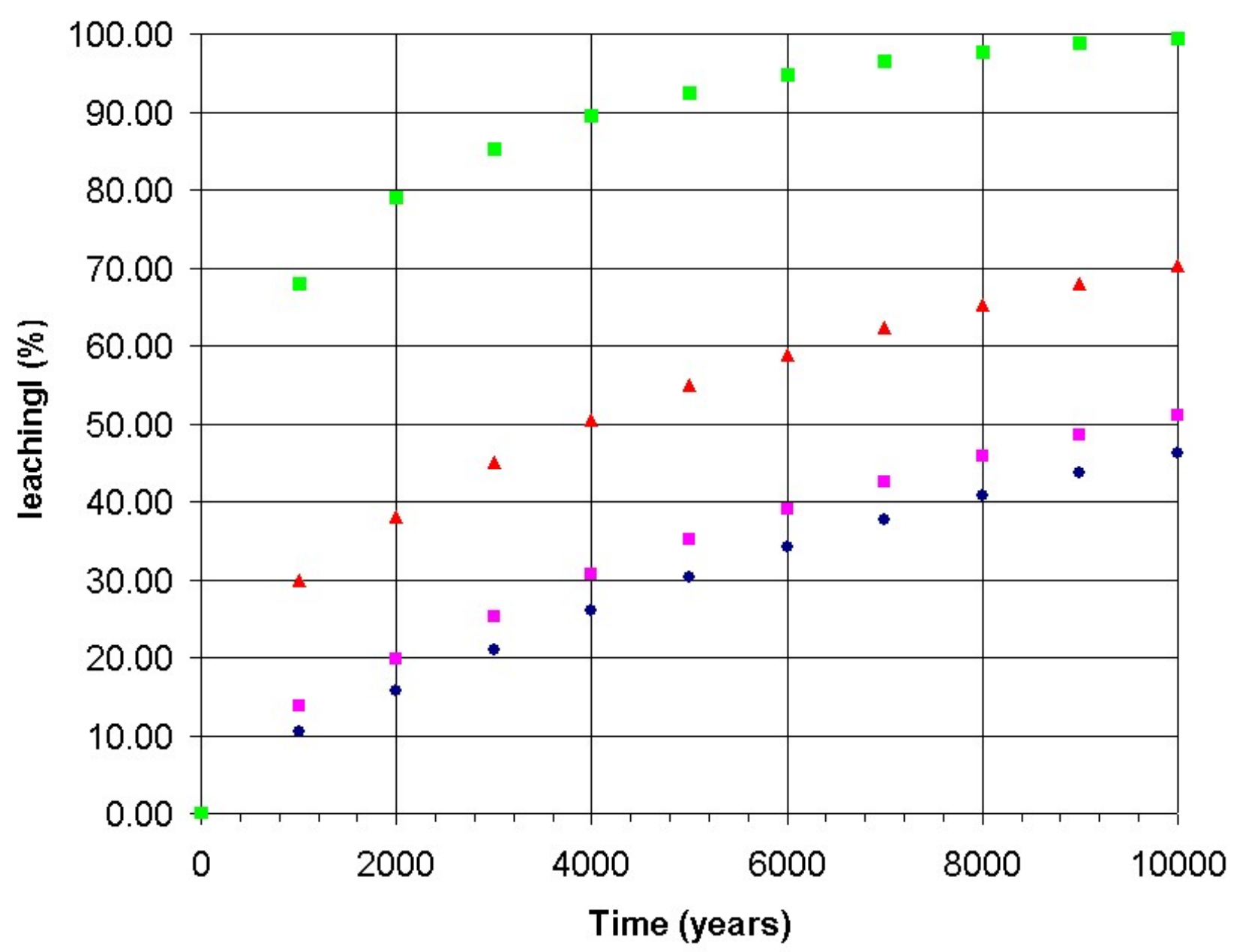

- Vault Concrete Diffusivity = Grout $/$ Saltstone Diffusivity $=1 \mathrm{e}-8 \mathrm{~cm}^{\wedge} 2 / \mathrm{sec}$

- Vault Concrete Diffusivity = Grout $/$ Saltstone Diffusivity $=1 \mathrm{e}-7 \mathrm{~cm} 2 / \mathrm{sec}$

$\Delta$ Vault Concrete Diffusivity = Grout $S$ Saltstone Diffusivity $=1 \mathrm{e}-6 \mathrm{~cm}^{\wedge} 2 / \mathrm{sec}$

- Vault Concrete Diffusivity = Grout $/$ Saltstone Diffusivity $=1 \mathrm{e}-5 \mathrm{~cm}^{\wedge} 2 / \mathrm{sec}$

Figure 5-4. Percent of Tc-99 released from the Saltstone Vault as a function of equal changes in both the Vault Concrete Diffusivity and the Grout/Saltstone Diffusivity.

An initial effort at introducing a continuous change to the properties as a function of time was performed. In this case, an assumption was made that the oxygen diffusion coefficient, Tc-99 diffusion coefficient, and the hydraulic conductivity of cement, change exponentially with time. Figure 5-5 shows the dependencies of Tc-99 release from the Saltstone Vault with various rates of the cement transformations with time. We consider four cases, i.e., properties do not change with time (no transformations), decrease of the diffusion and hydraulic conductivities by a factor of 10 within 10,000 years (transformation rate $=10$ ), decrease of 
the diffusion and hydraulic conductivities by a factor of 100 within 10,000 years (transformation rate $=100$ ), and an increase of the diffusion and hydraulic conductivities by a factor of 10 within 10,000 years (transformation rate $=0.1$ ).

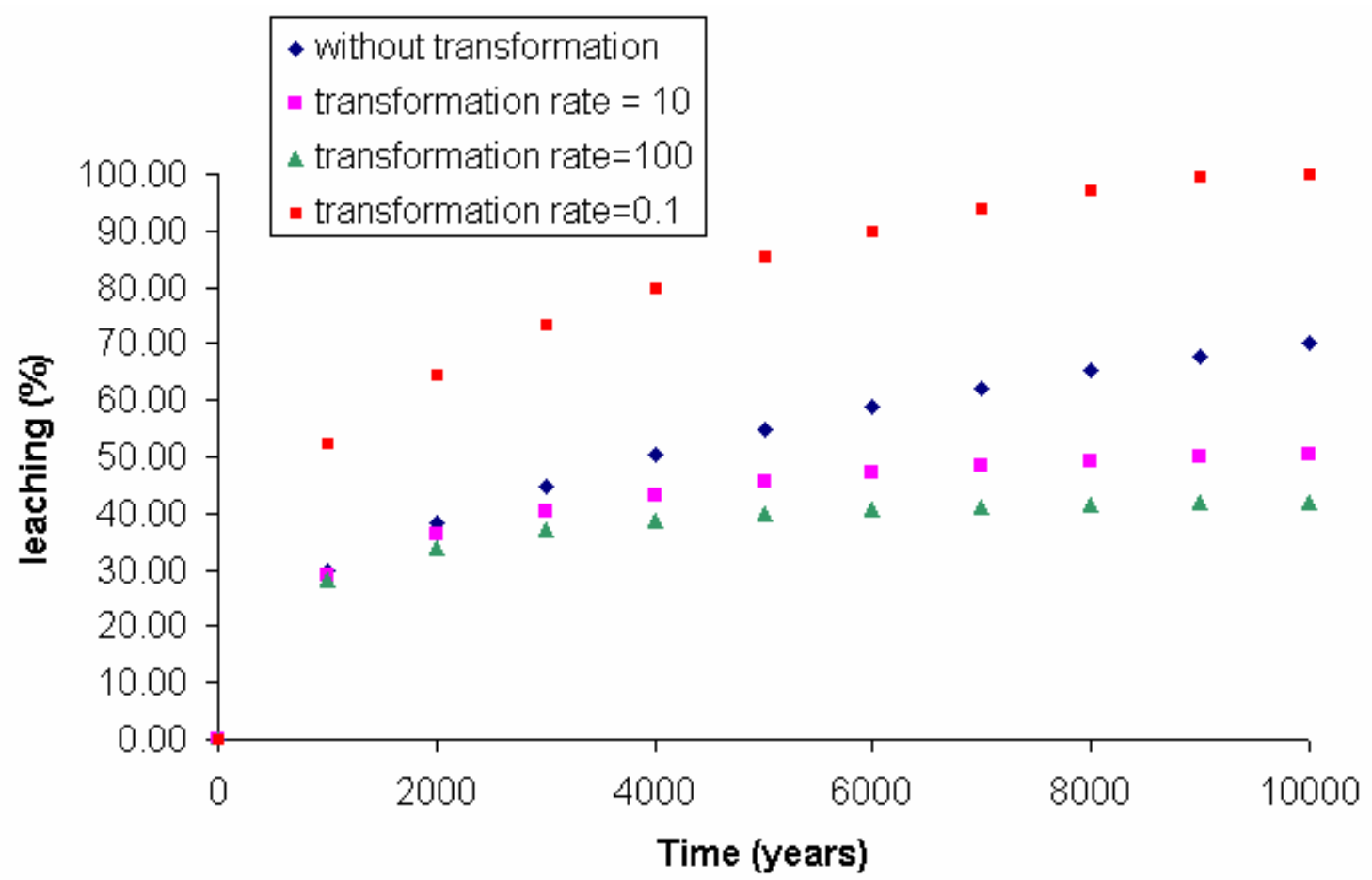

Figure 5-5 Percent of Tc-99 Released from the Saltstone Vault at Various Rates of Cement Transformations with Time. The starting conditions are $10^{-8} \mathrm{~cm} / \mathrm{sec}$ for the hydraulic conductivity, $1.9 \mathrm{E}-11 \mathrm{~cm}^{2} / \mathrm{sec}$ for the Tc-99 diffusivity, and $10^{-6} \mathrm{~cm}^{2} / \mathrm{sec}$ for the oxygen diffusivity in both the vault concrete and the Saltstone.

\subsection{Conclusions}

The inclusion of modeling the release of radionuclides from Saltstone and the concrete vault in which it is contained integrates the experimental findings with dose rate calculations at the regulatory point of compliance. The low effective diffusivity for Tc-99 in the reduced state measured as part of the work on Tc-99 immobilization demonstrates a very slow release of Tc-99 from Saltstone and the vault. However if the Saltstone and vault concrete degrade with time, oxygen infiltration, reductant and pertechnetate oxidation, and pertechnetate ion diffusion and advection lead to significant release of the Tc-99 over 10,000 years.

The initial sensitivity studies and the results included here provide insight into the increases in hydraulic conductivity and diffusivity that must be achieved prior to significant release of Tc-99. 
The outputs of this modeling can serve as input into the overall PA model which accounts for the Vadose Zone and migration to the water table and the point of compliance.

\subsection{RECOMMENDED PATH FORWARD}

Due to the fact that funding for Task 4 was discontinued due to the needs of higher priority tasks within the International Program, the tasks on selenium leaching and lower heats of hydration Saltstone formulations were not completed.

It is recommended that:

- Selenium leaching tests be conducted using both crushed and monolithic grout samples containing selenium at the lower bound of expected concentration in the Saltstone feed batches

- Selenium leaching tests be conducted both in the presence and absence of oxygen to determine the role of redox on leaching rates of Se-79 from Saltstone. That is, redox level determines the ratio of selenite $\left(\mathrm{SeO}_{3}{ }^{-2}\right)$ to selenate $\left(\mathrm{SeO}_{4}{ }^{-2}\right)$ within the grout and these species have previously been shown to have different leach rates.

- Heat of hydration be measured for formulations that substitute the ferro-spinel fly ash and silicon carbide (both of which were identified in this task as potential inert components) for slag and/or fly ash

- Perform calculations with PORFLOW that complete the analysis on the sensitivity of Tc99 release from Saltstone as a function of hydraulic conductivity

\subsection{REFERENCES}

[1] Variability Study for Saltstone, J. R. Harbour, T. B. Edwards, E. K. Hansen and V. J. Williams, WSRC-TR-2005-00447, Rev. 0, October 2005.

[2] Chemical Concentrations in Salt Solution Feed to the Saltstone Production Facility from $D D A$ and $A R P / M C U$ Batches, M. D. Drumm, M. A. Rios-Armstrong, and P. D d'Entremont, CBU-PIT-2005-00095, April, 2005.

[3] Special Analysis - Reevaluation of the Inadvertent Intruder, Groundwater, Air, and Radon Analyses for the Saltstone Disposal Facility, J. R. Cook, D. C. Kocher, L. McDowell-Boyer and E. L. Wilhite, WSRC-TR-2002-00456, Rev. 0, October, 2002.

[4] Challenging Applications for Hydrated and Chemically Reacted Ceramics, C. A. Langton, DP-MS-88-163, Rev. 0, 1988 
[5] Solidification/Stabilization of Technetium in Cement-Based Grouts, T. M. Gilliam, R. D. Spence, W. D. Bostick and J. L. Shoemaker, J. Hazard. Mater. 24, 189-197. 1990.

[6] Evolution of Technetium Speciation in Reducing Grout, W. W. Lukens, J. J. Bucher, D. K. Shuh and N. M. Edelstein, Environ. Sci. Technol., 39, 064-8070, 2005

[7] Technetium Speciation in Cement Waste Forms Determined by XANES, P. G. Allen, G. S. Siemering, D. K. Shuh, J. J. Bucher, N. M. Edelstein, C. A Langton, S. B. Clark, T. Reich, and M. A. Denecke, Radiochim. Acta, 76, 77-86, 1997.

[8] Stabilizing Grout Compatibility Study, J.R.Harbour, T.B.Edwards, T.H.Lorier, C.A.Langton, R.C.Moore, J.L.Krumhansl, K. C. Holt, F.Salas, and C.A.Sanchez,. WSRC-TR-2004-00021, Rev.0. (2004).

[9] Measurement of the Leachability of Solidified Low-Level Radioactive Wastes by a short-term Test Procedure, prepared by the American Nuclear Society Standards Committee Working Grout ANS-16.1, ANSI/ANS 16.1, 1986. Approved April 14, 1986 by the American National Standards Institute, Inc. American Nuclear Society, 555 N. Kensington Ave., La Grange Park, IL 60525 .

[10] Pretreatment of Tc-Containing Waste and Its Effect on Tc-99 Leaching from the Cement Compound, Albert S. Aloy, Elena N. Kovarskaya, John Harbour, Christine Langton, E. William. Holtzscheiter, MRS Proceedings, 2006 (in press).

[11] K.H.Lieser, Ch.Bauscher, Radiochemical Acta 42, no.4, pp.205-213 (1987)

[12] Radiation Safety Questions A.N.Mashkin, S.L.Shikov, J., Russia, Ozyorsk, PA «Mayak», No.1, pp. 12-17 (1999)

[13] A.F. Rapp. Proceedings of the International Conference on a Peaceful Use of Atomic Energy. Geneva, 1955. M.: Fizmatiz, 14, pp.86-103 (1958).

[14] A.N.Mashkin, A.V.Kobelev, Radiation Safety Questions J., Russia, Ozyorsk, PA «Mayak», No.3, pp. 36-41 (2000).

[15] N.Momoshima, M.Sayad, M.Yamada, M.Takamura, H.Kawamura, J. of Radioanalytical and Nuclear Chemistry, 266, No.3, pp.455-461 (2005). 
[16] ASTM D-5233, Standard Test Method for Single Batch Extraction Method for Waste Distribution», ASTM, Philadelphia, PA 19103 ( 1992, R 1999).

[17] The Sorption of Selenite of Various Cement Formulations, E. A. Johnson, M. J. Rudin, S. M. Steinberg, W. H. Johnson, Waste Management 20, 509-516, 2000.

[18] Mass Concrete, ACI207.1R-96, American Concrete Institute, 1996.

[19] Measurement of Thermal Properties of Saltstone, J. L. Steimke and M. D. Fowley, WSRCTR-97-00357, 1997.

[20] Differential Microcalorimeter, B.A. Golubev, Yu.V. Kondratiev, and B.I. Shetel'man, Russian Federation Inventor's Certificate \# 1283553, October 15, 1986

[21] Estimation of the Degree of Hydration of Blended Cement Pastes by a Scanning Electron Microscopy Point-counting Procedure, X. Feng, E. J. Garboczi, D. P. Bentz, P. E. Stutzman, and T. O. Mason, Cem. Concr. Res. 34,1787-1793, 2004.

[22] Estimated Duration of the Subsurface Reducing Environment produced by the Z-Area Saltstone Disposal Facility, D. I. Kaplan, and T Hang, WSRC-RP-200-00362, Rev 2, 2003 